\title{
Prevalence and Evolution of Noroviruses between 1966 and 2019, Implications for Vaccine Design
}

\author{
Hong-Lu Zhou ${ }^{1,+}{ }^{\mathbb{D}}$, Li-Na Chen ${ }^{1,+}{ }^{\text {, }}$, Song-Mei Wang ${ }^{2,+}{ }^{+}$, Ming Tan ${ }^{3,4}{ }^{\mathbb{D}}$, Chao Qiu ${ }^{1}$, Tian-Yi Qiu ${ }^{5, *}$ \\ and Xuan-Yi Wang 1,6,7,*
}

1 Key Laboratory of Medical Molecular Virology of MoE \& MoH and Institutes of Biomedical Sciences, Fudan University, Shanghai 200032, China; 16111510020@fudan.edu.cn (H.-L.Z.); 20111510055@fudan.edu.cn (L.-N.C.); qiuchao@fudan.edu.cn (C.Q.)

2 Laboratory of Molecular Biology, Training Center of Medical Experiments, School of Basic Medical Sciences, Fudan University, Shanghai 200032, China; smwang2@fudan.edu.cn

3 Division of Infectious Diseases, Cincinnati Children's Hospital Medical Center, Cincinnati, OH 45229, USA; ming.tan@cchmc.org

4 College of Medicine, University of Cincinnati, Cincinnati, OH 45229, USA

5 Zhong Shan Hospital, Shanghai Public Health Clinical Center, Shanghai Medical College, Fudan University, Shanghai 201508, China

6 Children's Hospital, Fudan University, Shanghai 200062, China

7 Shanghai Institute of Infectious Disease and Biosecurity, Shanghai 200032, China

* Correspondence: qiutianyi@shphc.org.cn (T.-Y.Q.); xywang@shmu.edu.cn (X.-Y.W.); Tel.: +86-188-1736-6327 (T.-Y.Q.); +86-21-5423-7865 (X.-Y.W.)

+ Contribution, H.-L.Z., L.-N.C. and S.-M.W. contributed equally.

Citation: Zhou, H.-L.; Chen, L.-N.; Wang, S.-M.; Tan, M.; Qiu, C.; Qiu, T.-Y.; Wang, X.-Y. Prevalence and Evolution of Noroviruses between 1966 and 2019, Implications for Vaccine Design. Pathogens 2021, 10, 1012. https://doi.org/10.3390/ pathogens10081012

Academic Editor: Carl Kirkwood

Received: 8 July 2021

Accepted: 3 August 2021

Published: 11 August 2021

Publisher's Note: MDPI stays neutra with regard to jurisdictional claims in published maps and institutional affiliations.

Copyright: (c) 2021 by the authors. Licensee MDPI, Basel, Switzerland. This article is an open access article distributed under the terms and conditions of the Creative Commons Attribution (CC BY) license (https:/ / creativecommons.org/licenses/by/ $4.0 /)$.
Abstract: Noroviruses (NoVs), a group of single-stranded RNA viruses causing epidemic acute gastroenteritis in humans, are highly diverse, consisting of multiple genogroups with $>30$ genotypes. Their continual evolutions make NoV vaccine design and development difficult. Here, we report a study of NoV sequences obtained from a population-based diarrhea surveillance in Zhengding County of Hebei Province spanning from 2001 to 2019 and those available in the GenBank database from 1966 to 2019. NoV genotypes and/or variants that may evade immunity were screened and identified based on primary and conformational structures for vaccine design. We selected 366, 301, 139,74 and 495 complete VP1-coding nucleotide sequences representing the predominant genotypes of GII.4, GII.2, GII.3, GII.6 and GII.17, respectively. A total of 16 distinct GII.4 variants were identified, showing a typical linear evolutionary pattern of variant replacement, while only 1-4 variants of the other genotypes were found to co-circulate over the 40-50-year period without typical variant replacement. The vaccine strain GII.4c is close to variant Sydney_2012 (0.053) in their primary structure, but they are distinct at epitopes A and E in conformations. Our data suggested GII.4 variant Sydney_2012, GII.2 variant A, a GII.3 strain, GII.6 variants B and C and GII.17 variant D are primary candidate strains for $\mathrm{NoV}$ vaccine development.

Keywords: norovirus; prevalence; evolution; homology modeling; immunogen

\section{Introduction}

Noroviruses (NoVs) are a common cause of acute gastroenteritis among young children worldwide [1]. They are RNA viruses constituting the Norovirus genus in the family Caliciviridae. Each NoV virion is encapsulated by an icosahedral protein capsid containing a positive-sense, single-stranded RNA genome in $\sim 7.7 \mathrm{~kb}$ with three open reading frames (ORFs) [2]. ORF1 encodes six non-structural proteins, while ORF2 and ORF3 encode the major (VP1) and the minor (VP2) structural proteins, respectively. Structure studies revealed that VP1 has two major regions, a N-terminal shell (S) and a C-terminal protruding (P) domain. The latter is further divided into the moderately conservative P1 and the 
highly variable P2 subdomains [3,4]. In vitro expression of VP1 results in self-assembled virus-like particles (VLPs), being composed of 90 VP1 dimers.

A standardized nomenclature has recently been proposed to classify NoVs into seven genogroups (GI-GVII) with at least 30 genotypes, based on the complete VP1 amino acid sequence [4]. Of these, genogroups GI and GII with 9 and 22 genotypes, respectively, primarily infect humans. Despite this extensive genetic diversity, genotype GII.4 is responsible for the majority of NoV outbreaks and epidemics worldwide [5]. However, two exceptions were noted recently, in which a GII.17 stain became predominant in East Asia during 2014-2015, and a GII.2 stain was predominant in Europe and Asia during 2016-2017 [6-10].

There is no commercial NoV vaccine so far. The fact that NoVs are diverse with multiple genogroups/genotypes circulating in human populations simultaneously and their continuous evolution make immunogen selection of a NoV vaccine difficult [2]. Although four vaccine candidates have entered clinical trials [11-13], different methods to tentatively select immunogens are still being debated. Thus, further molecular analyses of $\mathrm{NoV}$ evolution will shed light onto the design and development of NoV vaccines. Most of such previous studies focused on GenBank database or hospital-based surveillance [14-16], which may not reflect real evolutionary trends in nature. Therefore, a long time span, population-based surveillance in a particular locality are essential to examine the evolutionary dynamics of NoVs.

In this study, NoV genomic information was not only collected from GenBank database, but also from a population-based diarrhea surveillance. Through the orderly applications of epidemiology, bioinformatics and structural biology, a comprehensive understanding of the epidemiological characteristics, evolutionary patterns and structural changes of NoVs was achieved. Our findings suggested that non-GII.4 intra-genotypic variants displayed a striking genetic stability over long periods of time, with GII.4 as the notable exception, providing new insights into preliminary screening of candidate vaccine strains.

\section{Results}

\subsection{Global Temporal Dynamics of NoVs}

To reveal the global temporal dynamics of NoVs, 26,469 NoV sequences with confirmed capsid types, including 362 from our population-based surveillance in Zhengding Country, and 26,107 available in the GenBank database were collected to analyze the prevalence of NoV genotypes during the past 50 years (Figure 1). In the early years (1966 to 1991), an epidemic trend was difficult to observe, due to the fewer number of available sequences. The accessible sequences in the GenBank started to increase rapidly since 1992, when the first PCR method was established to detect NoVs. Particularly, more than $1000 \mathrm{NoV}$ sequences per year were deposited in the GenBank over the period from 2006 to 2017. From 2000 to 2013, the most prevalent genotype was GII.4, followed by GII.3. A sudden prevalence of GII.17 occurred in 2014, even surpassing GII.4 as the predominant genotype in 2015. An unexpected prevalence increase of GII.2 was also noted starting in 2016, and it has become the predominant genotype in recent years (2016-2019). In addition, although the prevalence of GII.6 was not as remarkable as the abovementioned ones, it has been steadily circulating as one of the top five epidemic genotypes since 2003. This global temporal dynamics indicates that the top five predominantly circulating genotypes are GII.4, GII.2, GII.3, GII.6 and GII.17. As a result, we began to further analyze their complete VP1 genes.

\subsection{Time-Scale Evolution of the Globally Collected NoV Strains}

A total of 2009 complete VP1-encoding nucleotide sequences of GII.4 were obtained from 1974 to 2019. To reduce the number of sequences while maintaining enough phylogenetic information, 366 of these sequences were selected based on criteria that at least one of each identified variant per country per year was included (Supplementary Table S1). Considering that fewer sequences $(<500$ sequences per genotype) were available for non-GII.4 genotypes, all available sequences were used in the analysis. As results, 301, 
139, 74 and 495 sequences were derived for genotypes GII.2, GII.3, GII.6 and GII.17, respectively (Table 1 ).

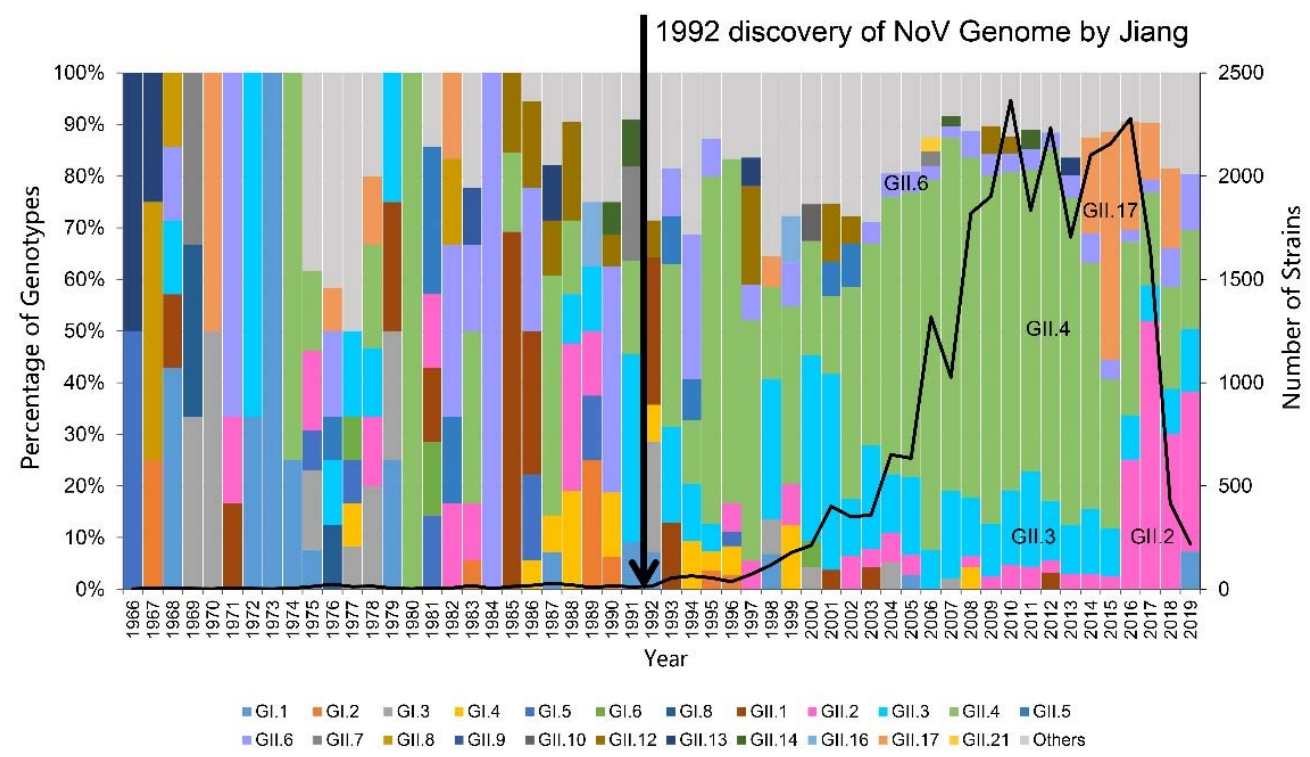

Figure 1. Global temporal dynamics of the prevalence of various norovirus genotypes over a period between 1966 and $2019(n=26,469)$. The percentage of the top five genotypes each year was presented, and the remaining genotypes are calculated as others.

Table 1. Summary of the norovirus sequences that were analyzed in this study.

\begin{tabular}{|c|c|c|c|c|}
\hline Genotypes & Variants & Sequences & Years & Time Span (Years) \\
\hline \multirow[t]{16}{*}{ GII.4 } & Bristol_1993 & 1 & 1987 & 1 \\
\hline & Camberwell_1994 & 11 & 1987-1988 & 2 \\
\hline & US95_96 & 13 & 1995-2004 & 10 \\
\hline & Farmington_Hills_2002 & 21 & 2002-2012 & 11 \\
\hline & Lanzhou_2002 & 3 & 2000-2002 & 3 \\
\hline & Asia_2003 & 27 & 2004-2011 & 8 \\
\hline & Kaiso_2003 & 2 & 2002-2003 & 2 \\
\hline & Hunter_2004 & 37 & $2002-2006$ & 5 \\
\hline & Yerseke_2006a & 34 & 2006-2015 & 10 \\
\hline & Den_Haag_2006b & 56 & 2006-2015 & 10 \\
\hline & Apeldoorn_2007 & 50 & 2007-2009 & 3 \\
\hline & Cairo_2007 & 2 & 2007 & 1 \\
\hline & Osaka_2007 & 23 & 2005-2011 & 6 \\
\hline & New_Orleans_2009 & 45 & 2008-2013 & 6 \\
\hline & Sydney_2012 & 40 & 2010-2019 & 10 \\
\hline & Hong_Kong_2019 & 1 & 2019 & 1 \\
\hline \multirow[t]{2}{*}{ GII.2 } & A & 299 & 1971-2019 & 49 \\
\hline & B & 2 & 2002 & 1 \\
\hline GII.3 & - & 139 & 1972-2019 & 48 \\
\hline \multirow[t]{3}{*}{ GII.6 } & A & 19 & 1971-2012 & 49 \\
\hline & B & 18 & 1976-2019 & 44 \\
\hline & $\mathrm{C}$ & 37 & 1977-2019 & 43 \\
\hline \multirow[t]{4}{*}{ GII.17 } & A & 8 & 1978-2016 & 39 \\
\hline & B & 1 & 2005 & 1 \\
\hline & $\mathrm{C}$ & 26 & 2013-2015 & 3 \\
\hline & $\mathrm{D}$ & 460 & 2013-2019 & 7 \\
\hline
\end{tabular}


The GII.4 NoVs have been known to accumulate nucleotide substitutions in a clocklike manner for more than 30 years and diverged into 16 variants, showing periodic substitution of dominant variants. Presently, the main epidemic GII.4 strain is variant Sydney_2012 (Figure 2a). Considering the source of sequences from the GenBank was mixed and confounding, the variation rules of GII.4 were verified by the sequences collected from our long-term longitudinal and multi-sectional diarrhea surveillance in Zhengding County, Hebei Province (Figure 2b). Strikingly, it showed a similar evolutionary trend, confirming the consistency and reliability of the outcomes of the above analyses.

(a) GII.4

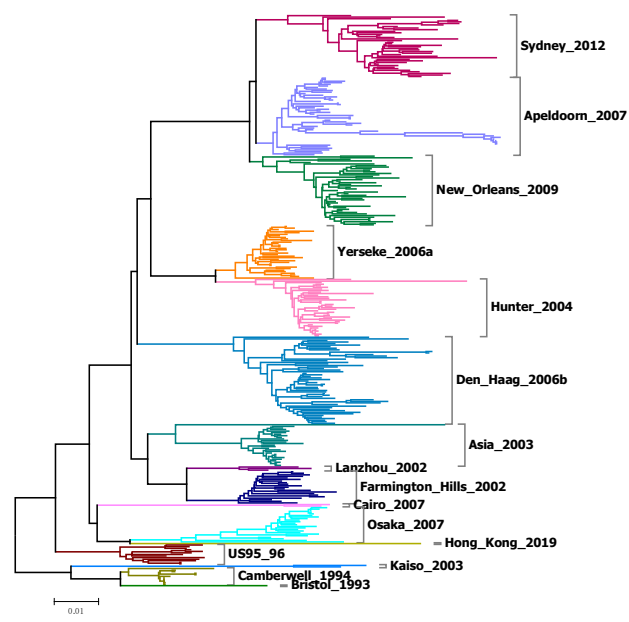

(b) GII.4 (Zhengding Surveillance)

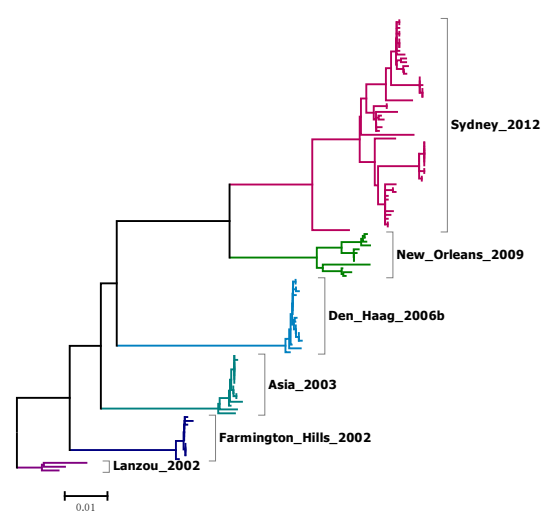

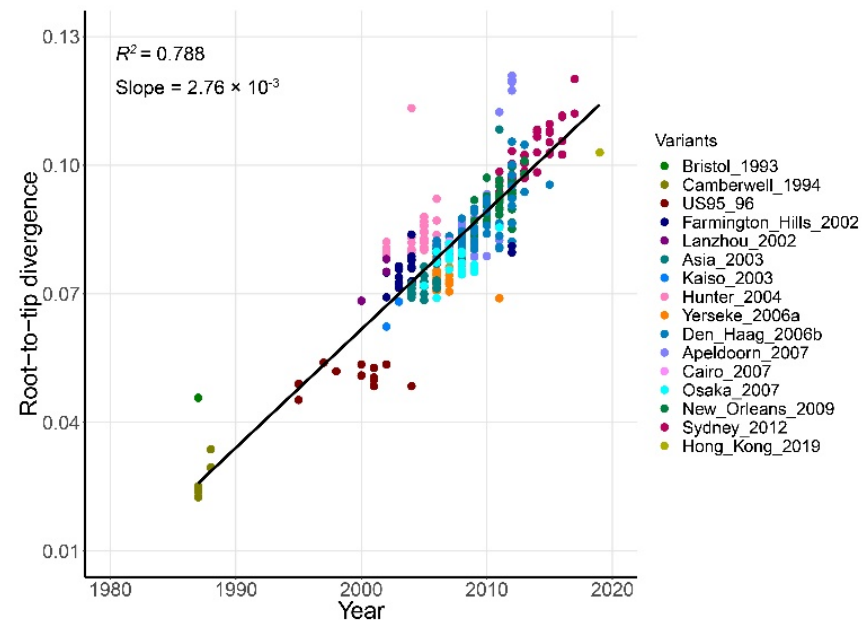

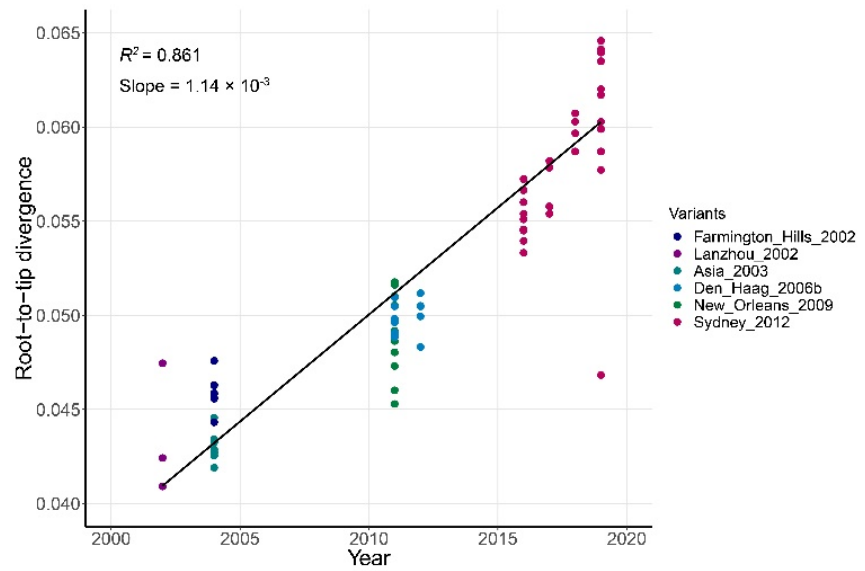

Figure 2. Cont. 
(c) GII.2
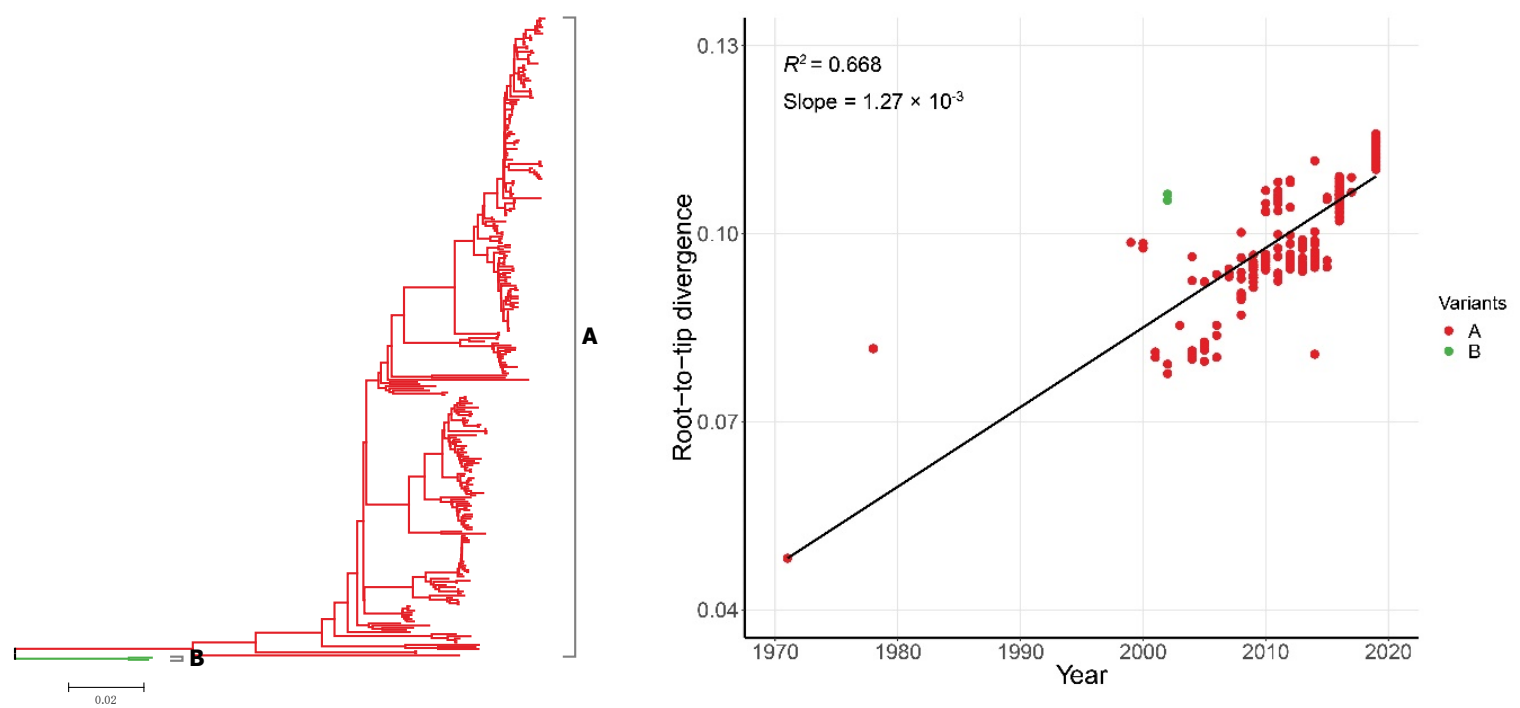

(d) GII.3
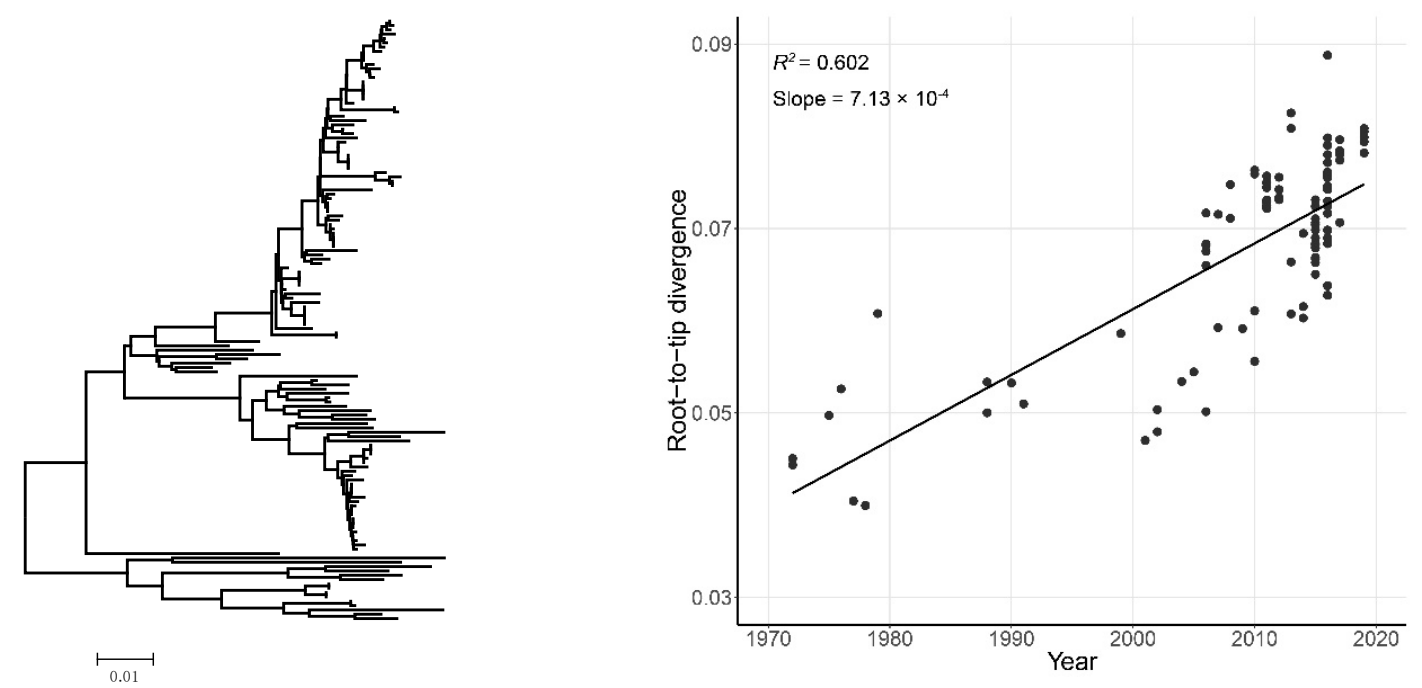

(e) GII.6
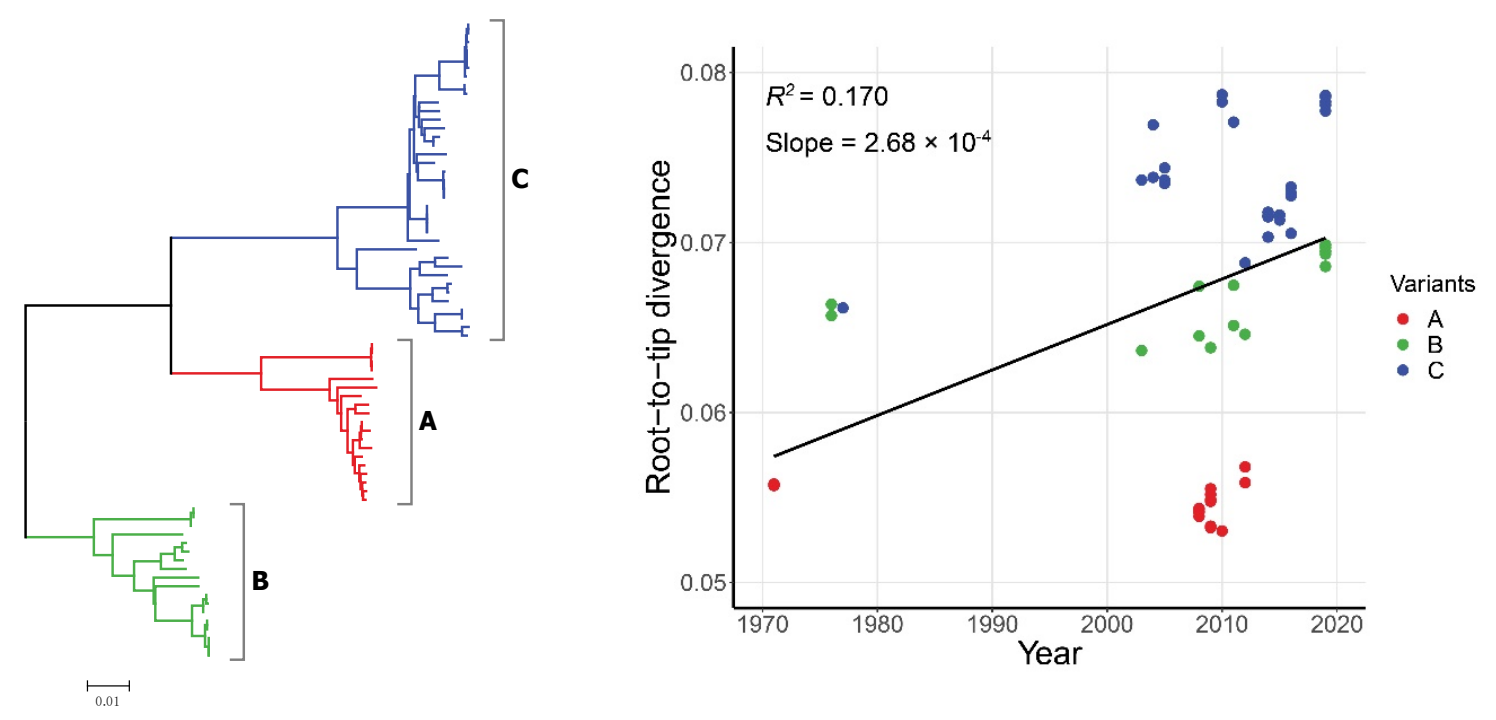

Figure 2. Cont. 


\section{(f) GII.17}
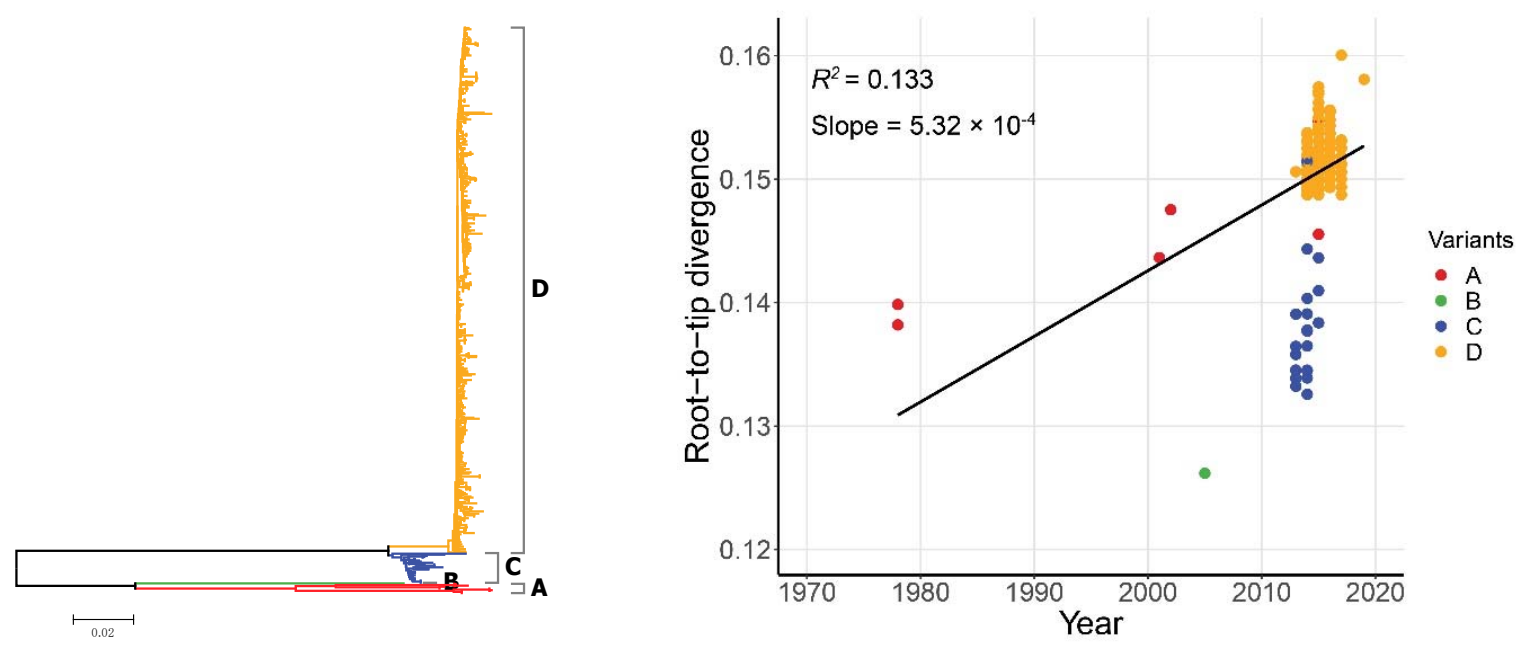

Figure 2. Phylogenetic trees and the corresponding root-to-tip divergence plots of the complete capsid genes (ORF2) of noroviruses. VP1-encoding nucleotide sequences of GII.4 (a), GII.4 from Zhengding surveillance (b), GII.2 (c), GII.3 (d), GII.6 (e) and GII.17 (f) genotypes are shown. The x-axis indicates the collection years, and the y-axis shows the root-to-tip divergence on the neighbor joining phylogenetic tree. The black line indicates a linear regression line of the root-to-tip divergence and collection years. Each circle presents a strain, and each color indicates a specific variant.

Unlike the GII.4 NoVs, the dominant variants in other genotypes appeared persist and co-circulate for 40-50 years without replacement or turnover of variants (Figure 2c-f). For example, GII. 2 contained two variants, A and B. While 299 out of 301 sequences were from variant $A$ that circulated from 1971 to 2019, only two sequences were variant $B$ that emerged in 2002. Notably, only a single variant existed in GII.3 that circulated from 1972 to 2019. Three GII.6 variants (A, B, and C) were found to co-circulate since the 1970s, but only B and C existed after 2012. Finally, four GII.17 variants (A to D) were identified, among which variant A circulated over the longest period ranging from 1978 to 2016, but variant $\mathrm{D}$ has been the most prevalent one in recent years. The phylogenetic root-to-tip divergence plot showed a strong clock-like signal with coefficient of determination $\left(R^{2}\right)$ between 0.602 and 0.788 for GII.4, GII.2 and GII.3 genotypes, while GII.6 and GII.17 appeared to lack such clock-like evolution with $\mathrm{R}^{2}$ between 0.133 and 0.170 .

To reconstruct the time-scale of each NoV genotype, the complete VP1 gene sequences were used for Bayesian coalescent analysis (Table 2). The results showed that the nucleotide substitution rates were estimated highest using UCED, followed by UCLN and strict clock, regardless of genotypes. When compared in the same molecular model, the highest nucleotide substitution rate was estimated in genotype GII.4 $\left(4.95-5.91 \times 10^{-3}\right.$ nucleotide substitutions/site/year), followed by GII.3 (3.40-3.59 $\times 10^{-3}$ nucleotide substitutions/site/year), GII.2 (2.30-3.16 × 10-3 nucleotide substitutions/site/year), GII.6 (2.39-3.07 $\times 10^{-3}$ nucleotide substitutions/site/year), and GII.17 (1.54-1.98 $\times 10^{-3}$ nucleotide substitutions/site/year). The dates of the most recent ancestor could be traced back to 1791.9-1868.6 for GII.17, then 1855.6-1897.0 for GII.6, 1930.7-1945.5 for GII.2, 1967.1-1968.0 for GII.3 and 1980.5-1981.4 for GII.4. Notably, when GII.4 was confined to the same area (Zhengding County of our surveillance), the nucleotide substitution rate appeared to be lower, with $1.55-2.97 \times 10^{-3}$ nucleotide substitutions/site/year.

In addition, these Bayes factor values served as evidence that UCED was the best fit model for assessing the evolutionary history of the VP1 genes. Therefore, the MCC tree of complete VP1 genes was estimated by UCED using a Bayesian skyline demographic model (Figure 3). The results showed that GII.4 variants diverge from each other long before emerging to spread pandemically, indicating ongoing undetected circulation of pre-pandemic variants at a low level (Figure 3a,b). For the non-GII.4 genotypes, variant B of GII.2 that transiently emerged in 2002 may have started to diverge from variant A 
in 1962.2 (Figure 3c). Interestingly, GII.3 NoVs have been diverging among themselves with slight cumulative changes over time, although a new variant has not yet emerged (Figure 3d). Moreover, one branch of GII.6 began to diverge into variant C in 1906.0, and the other branch diverged into variants A and B in 1931.4 (Figure 3e). The divergent time of GII.17 variant C and D were estimated to be 2001.1 (Figure 3f).

Table 2. Nucleotide substitution rates and divergence times of norovirus VP1 genes over the past 30-50 years.

\begin{tabular}{|c|c|c|c|c|c|c|}
\hline \multirow{2}{*}{ Genotypes } & \multirow{2}{*}{ Years } & \multirow{2}{*}{$\begin{array}{c}\text { No. of } \\
\text { Sequences }\end{array}$} & \multirow{2}{*}{ Molecular Clock } & \multirow{2}{*}{$\begin{array}{c}\text { Nucleotide Substitution Rate } \\
10^{-3} \text { Substitution/Site/Year } \\
\text { (95\% HPD) }\end{array}$} & \multicolumn{2}{|c|}{ TMRCA } \\
\hline & & & & & No. of Years & Dates (Ranges) \\
\hline \multirow{3}{*}{ GII.4 } & \multirow{3}{*}{ 1987-2019 } & \multirow{3}{*}{366} & Strict Clock & $4.95(4.53-5.39)$ & $38.5(37.0-40.1)$ & 1980.5 (1978.9-1982.0) \\
\hline & & & UCLN & $5.37(4.84-5.88)$ & $38.4(34.7-43.5)$ & $1980.6(1975.5-1984.3)$ \\
\hline & & & UCED & $5.91(5.33-6.52)$ & $37.6(33.7-43.2)$ & $1981.4(1975.8-1985.3)$ \\
\hline \multirow{3}{*}{$\begin{array}{c}\text { GII.4 } \\
\text { (Zhengding) }\end{array}$} & \multirow{3}{*}{ 2002-2019 } & \multirow{3}{*}{119} & Strict Clock & $1.55(1.17-2.01)$ & $51.2(38.5-63.7)$ & 1967.8 (1955.3-1980.5) \\
\hline & & & UCLN & $1.67(1.10-2.52)$ & $50.3(29.5-70.4)$ & 1968.7 (1948.6-1989.5) \\
\hline & & & UCED & $2.97(1.48-4.43)$ & $32.3(17.9-56.1)$ & 1986.7 (1962.9-2001.1) \\
\hline \multirow{3}{*}{ GII.2 } & \multirow{3}{*}{ 1971-2019 } & \multirow{3}{*}{301} & Strict Clock & $2.30(2.01-2.60)$ & $88.3(79.1-97.4)$ & 1930.7 (1921.6-1939.9) \\
\hline & & & UCLN & $2.68(2.19-3.20)$ & $81.5(60.5-105.6)$ & 1937.5 (1913.4-1958.5) \\
\hline & & & UCED & $3.16(2.52-3.76)$ & $73.5(55.0-99.3)$ & 1945.5 (1919.7-1964.0) \\
\hline \multirow{3}{*}{ GII.3 } & \multirow{3}{*}{ 1972-2019 } & \multirow{3}{*}{139} & Strict Clock & $3.40(3.00-3.80)$ & $51.0(49.3-52.9)$ & 1968.0 (1966.1-1969.7) \\
\hline & & & UCLN & $3.51(2.99-4.04)$ & $50.9(47.3-55.1)$ & 1968.1 (1963.9-1971.7) \\
\hline & & & UCED & $3.59(2.99-4.21)$ & $51.9(47.0-60.1)$ & 1967.1 (1958.9-1972.0) \\
\hline \multirow{3}{*}{ GII.6 } & \multirow{3}{*}{ 1971-2019 } & \multirow{3}{*}{74} & Strict Clock & $2.39(1.98-2.83)$ & $163.4(136.0-192.1)$ & 1855.6 (1826.9-1883.0) \\
\hline & & & UCLN & $2.64(1.96-3.34)$ & $142.3(96.9-189.6)$ & 1876.7 (1829.4-1922.1) \\
\hline & & & UCED & $3.07(1.86-4.28)$ & $122.0(68.1-193.7)$ & $1897.0(1825.3-1950.9)$ \\
\hline \multirow{3}{*}{ GII.17 } & \multirow{3}{*}{ 1978-2019 } & \multirow{3}{*}{495} & Strict Clock & $1.54(1.29-1.79)$ & $227.1(183.1-274.2)$ & 1791.9 (1744.8-1835.9) \\
\hline & & & UCLN & $1.94(1.26-2.65)$ & $157.5(67.5-276.0)$ & 1861.5 (1743.0-1951.5) \\
\hline & & & UCED & $1.98(1.37-2.60)$ & $150.4(74.5-253.4)$ & $1868.6(1765.6-1944.5)$ \\
\hline
\end{tabular}

Note: UCLN, uncorrelated lognormal relaxed clock. UCED, uncorrelated exponential relaxed clock. TMRCA, time to the most recent common ancestor. 95\% HPD: 95\% highest probability density.

\subsection{Genetic Distances Based on Amino Acid of Complete VP1s}

At present, the main epidemic strains of NoVs are Sydney_2012 of GII.4, variant A of GII.2, genotype GII.3 and variant B and C of GII.6, as well as variant D of GII.17. The mean amino acid distances among these main epidemic strains and the vaccine strain GII.4c of a vaccine candidate that is currently under a phase IIb clinical trial [17] were calculated (Table 3). The vaccine strain GII.4c is closest to Sydney_2012 of GII.4 (0.053) but further away from the other epidemic strains of heterologous genotypes (0.319-0.354). This raises concerns about the protective efficacy of the vaccine candidate against NoVs of heterologous genotypes.

Table 3. The amino acid distances among the main epidemic norovirus strains and vaccine strain GII.4c.

\begin{tabular}{ccccccc}
\hline Variants & $\begin{array}{c}\text { Vaccine } \\
\text { GII.4c }\end{array}$ & $\begin{array}{c}\text { GII.4 } \\
\text { Sydney_2012 }\end{array}$ & $\begin{array}{c}\text { GII.2 } \\
\text { Variant A }\end{array}$ & $\begin{array}{c}\text { GII.3 } \\
\text { Genotype }\end{array}$ & $\begin{array}{c}\text { GII.6 } \\
\text { Variant B }\end{array}$ & $\begin{array}{c}\text { GII.6 } \\
\text { Variant C }\end{array}$ \\
\hline GII.4 & 0.053 & & & & & \\
Sydney_2012 & & & & & & \\
GII.2 Variant A & 0.354 & 0.355 & & & & \\
GII.3 Genotype & 0.319 & 0.338 & 0.299 & & & \\
GII.6 Variant B & 0.348 & 0.357 & 0.284 & 0.265 & & \\
GII.6 Variant C & 0.342 & 0.352 & 0.301 & 0.261 & 0.076 & \\
GII.17 Variant D & 0.335 & 0.335 & 0.278 & 0.278 & 0.280 & 0.272 \\
\hline
\end{tabular}




\section{(a) GII.4}

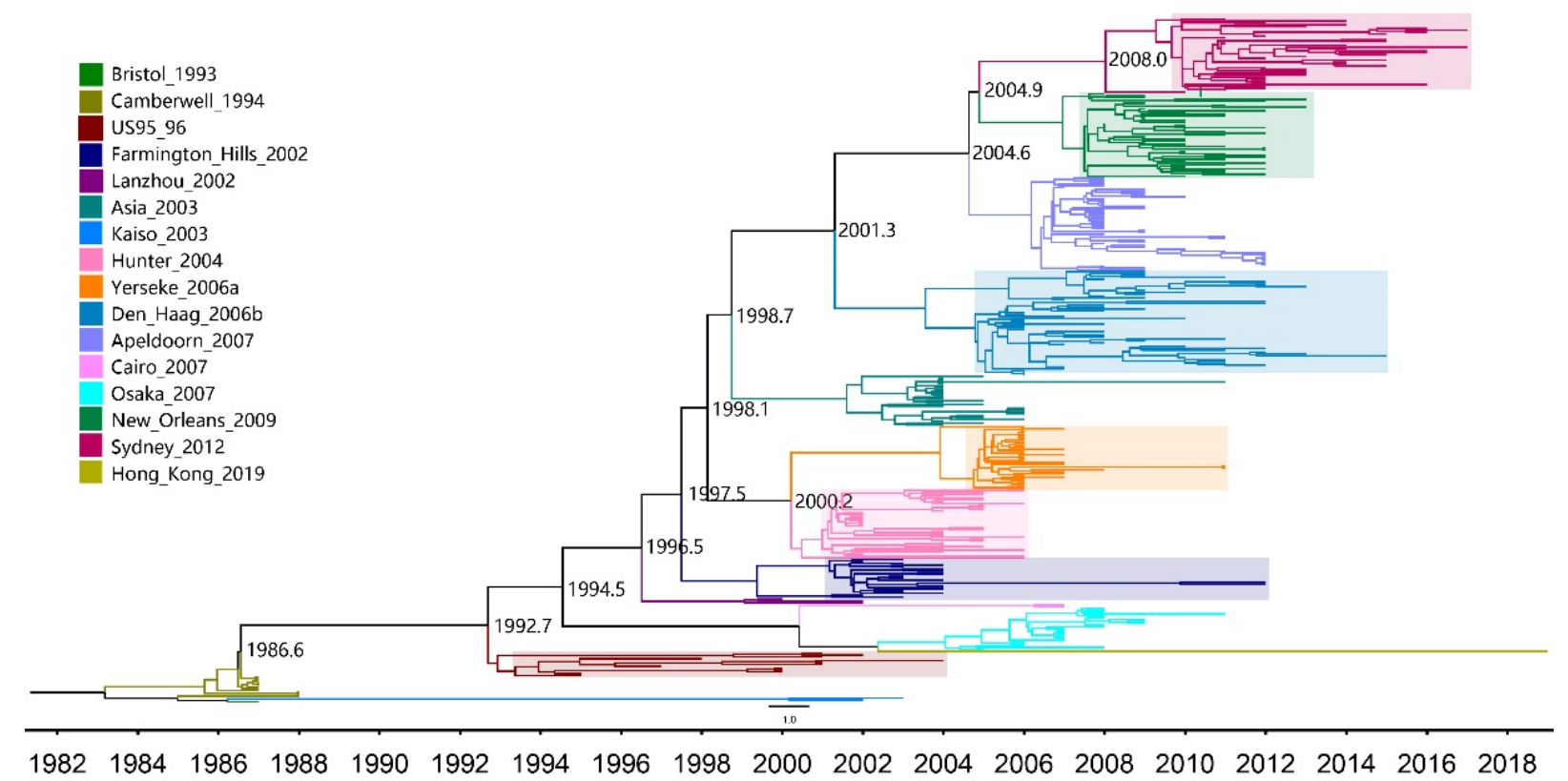

\section{(b) GII.4 (Zhengding Surveillance)}

Farmington_Hills_2002

Lanzhou_2002

Asia_2003

Den_Haag_2006b

New_Orleans_2009

Sydney_2012

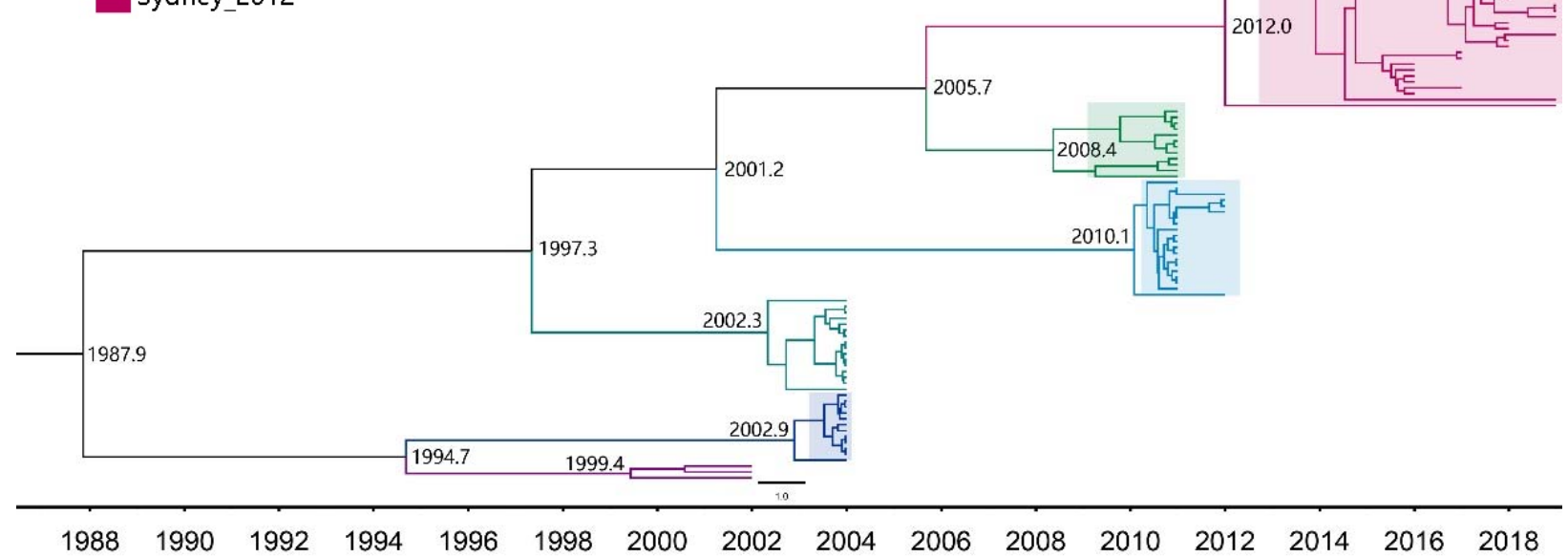

Figure 3. Cont. 
(c) GII.2

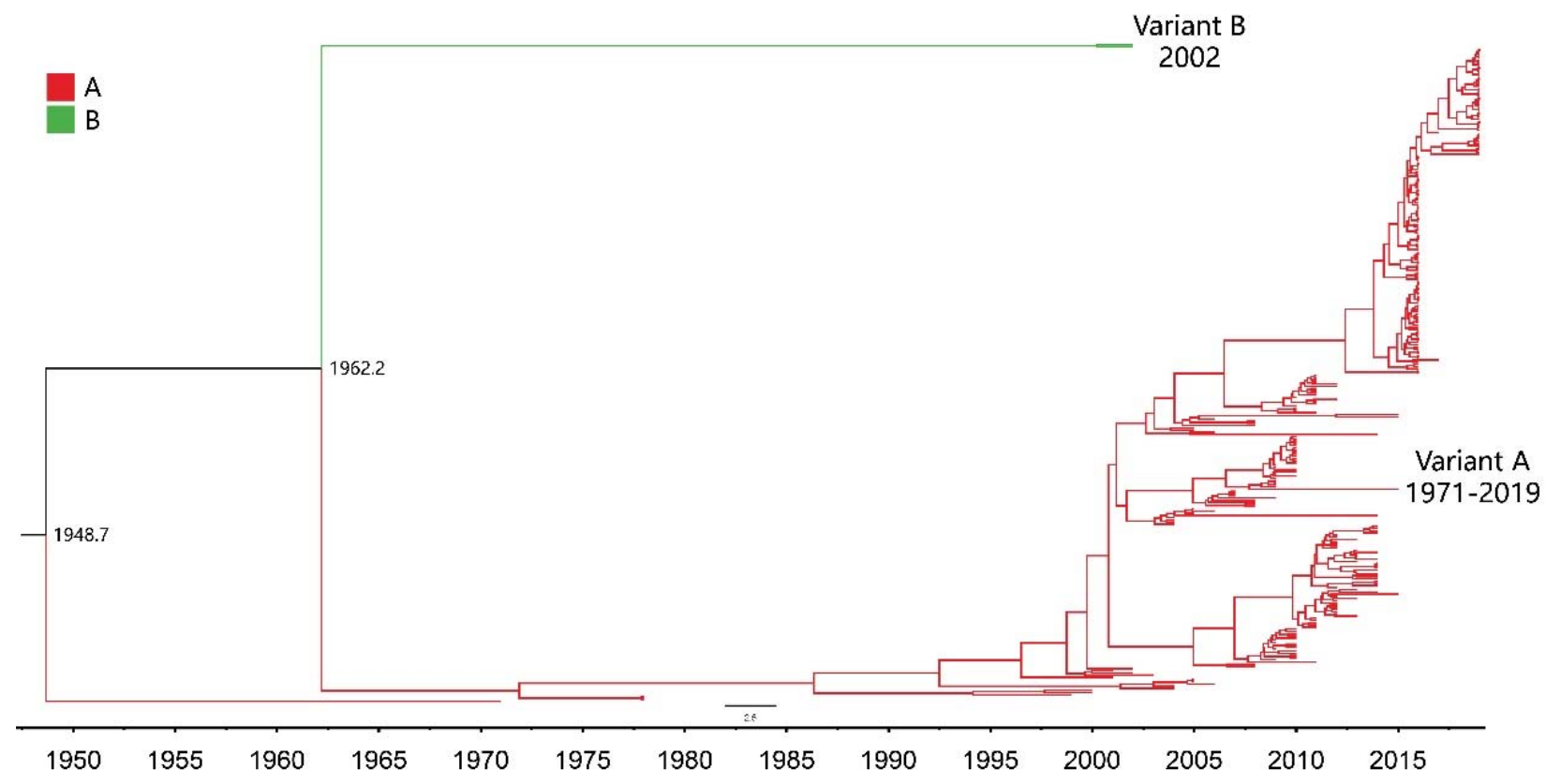

(d) GII.3

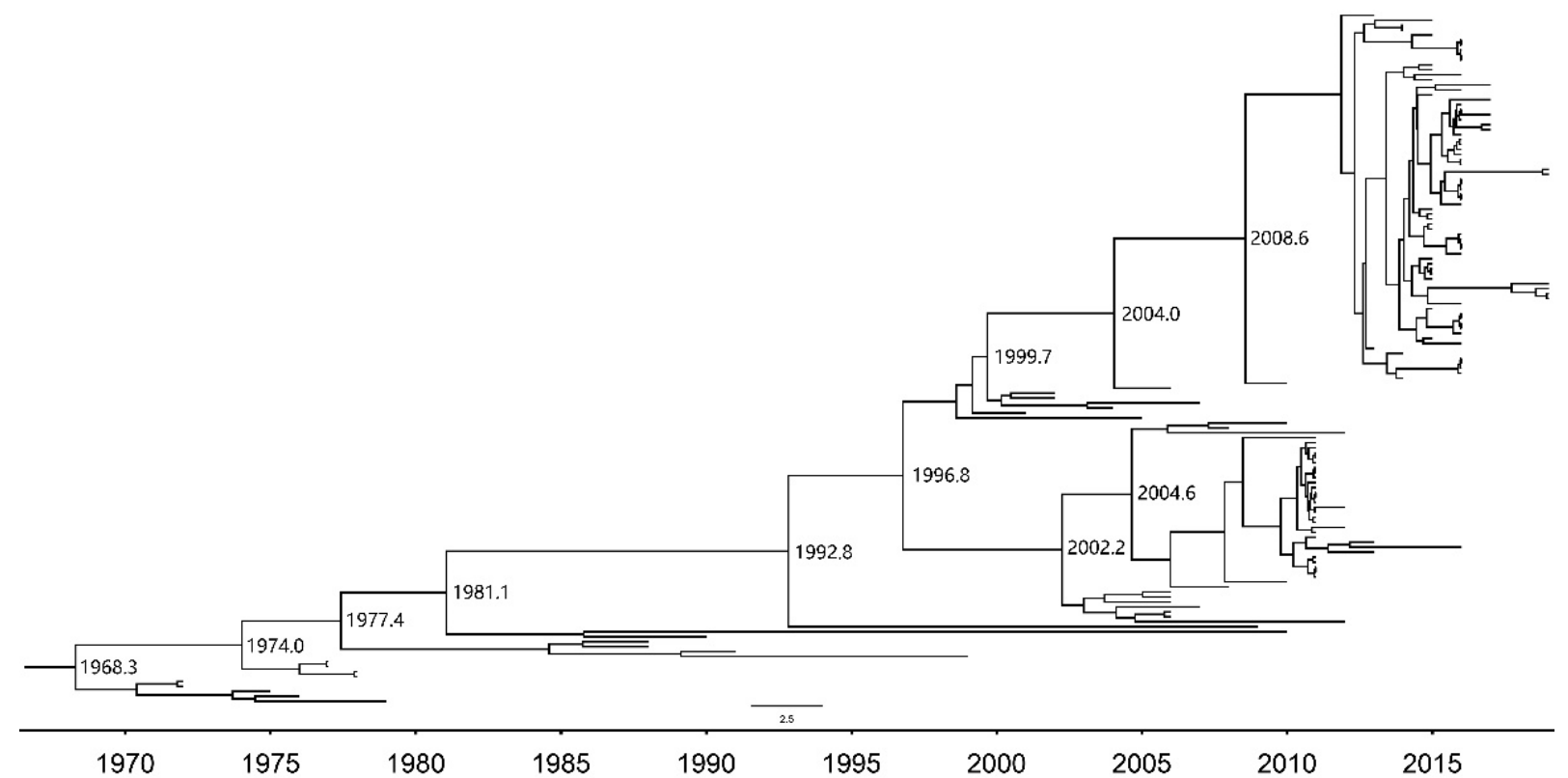

Figure 3. Cont. 


\section{(e) GII.6}

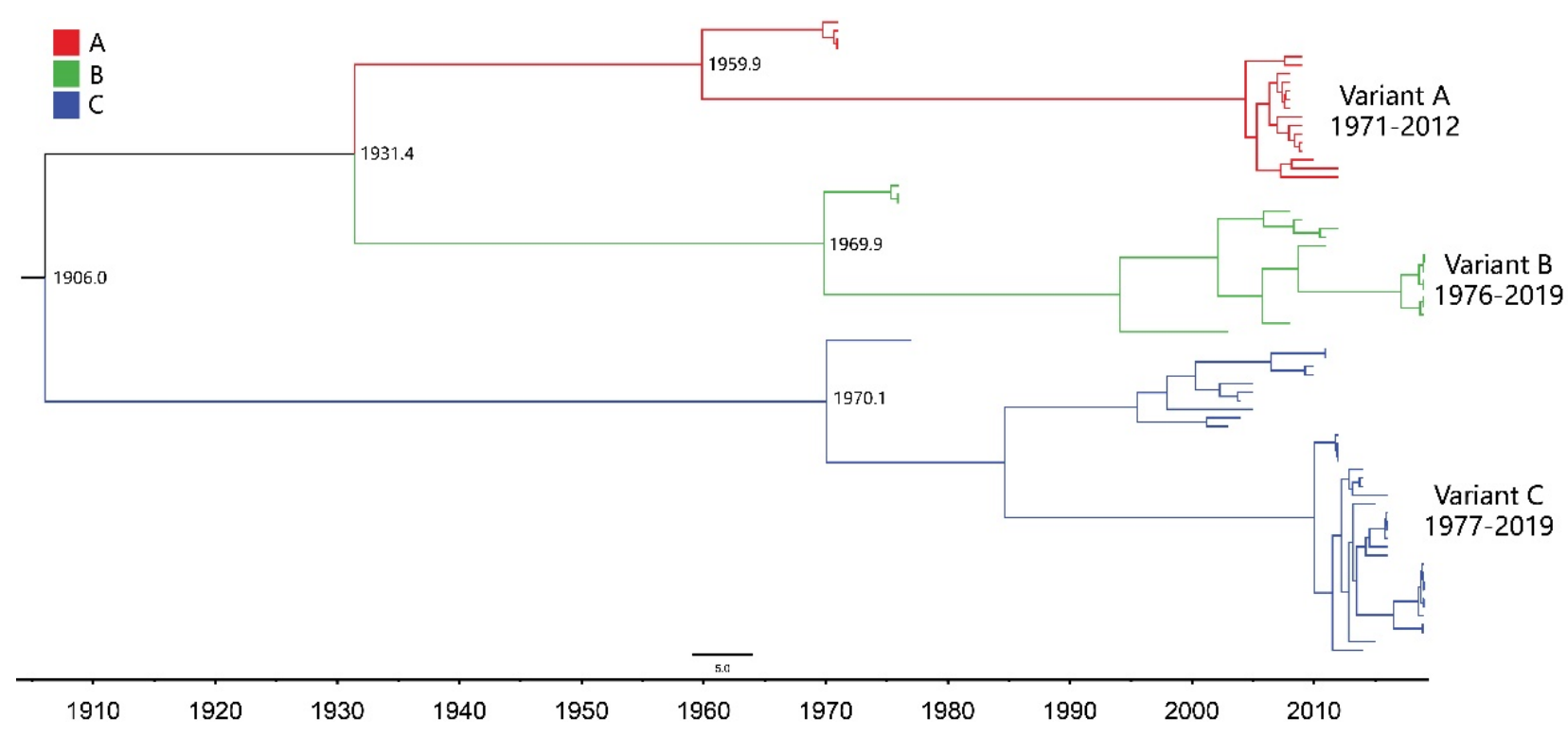

(f) GII.17

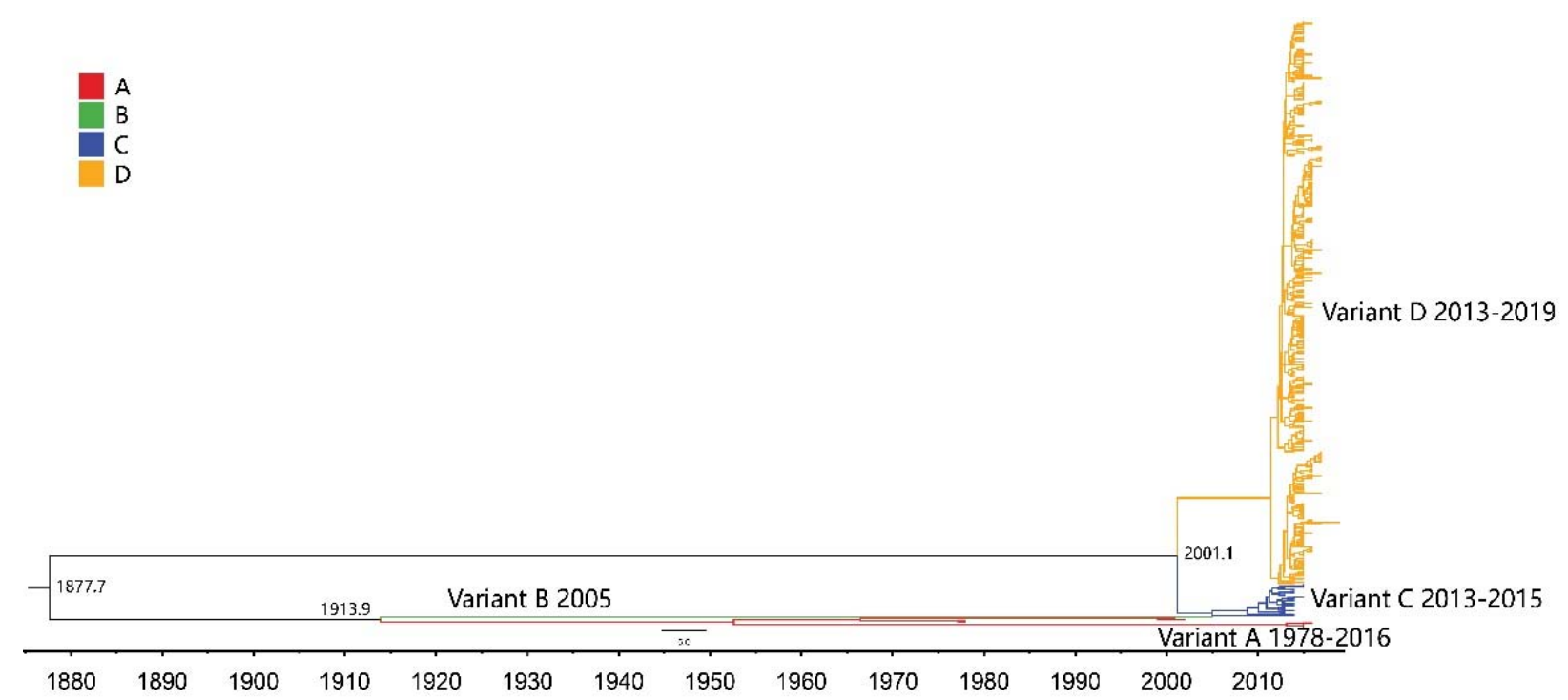

Figure 3. MCC tree based on complete capsid-encoding genes (ORF2s) of noroviruses. VP1-encoding nucleotide sequences of GII.4 (a), GII.4 from Zhengding surveillance (b), GII.2 (c), GII.3 (d), GII.6 (e) and GII.17 (f) genotypes. The trees were made using GTR + G + I nucleotide substitution model, an uncorrelated exponential clock (UCED) model and the Bayesian skyline as a tree prior. Each variant is shown by a specific color. A pandemic emergence of GII.4 is represented by the shaded area.

\subsection{Evolution of the GII.4 Blockade Epitopes}

Previous studies have identified five blockade epitopes in VP1 of GII.4, referred as epitope A $(294,296-298,368,372), B(333,382), C(340,376)$, D (393-395) and E $(407,412-413)$, respectively [18]. By mapping the amino acid compositions of each variant over the past three decades (Figure $4 a$ ), we found that the five epitopes changed dynamically over time. For example, the amino acid at position 298 of epitope A was an aspartic acid (ASP, D) in variants Bristol_1993, Camberwell_1994 and US95_96. This residue mutated into an asparagine (Asn, N) in variant Farmington Hill_2002 that emerged in 2002 and remained the same until it was replaced by a glutamine (Gln, Q) in new variant, HongKong_2019, 
which emerged in 2019. It should be noted that aspartic acid is a negatively changed acidic amino acid, while asparagine is neutral, indicating a substantial property change. Other examples, including mutations Q376E (epitope C), D393N (epitope D) and N407D (epitope E), may also represent significant physic-chemical changes that could lead to critical alteration of the corresponding epitopes (Figure 4a).

(a)

\begin{tabular}{|c|c|c|c|c|c|c|c|c|c|c|c|c|c|c|c|c|}
\hline \multirow{3}{*}{ Strains } & \multicolumn{16}{|c|}{ Epitopes } \\
\hline & \multicolumn{6}{|c|}{$\mathrm{A}$} & \multicolumn{2}{|c|}{$\mathrm{B}$} & \multicolumn{2}{|c|}{$\mathrm{C}$} & \multicolumn{3}{|c|}{$\mathrm{D}$} & \multicolumn{3}{|c|}{$\mathrm{E}$} \\
\hline & 294 & 296 & 297 & 298 & 368 & 372 & 333 & 382 & 340 & 376 & 393 & 394 & 395 & 407 & 412 & 413 \\
\hline GII.4c (vaccine) & A & $\mathrm{T}$ & $Q$ & $E$ & $\mathrm{~S}$ & $\mathrm{~S}$ & V & $\mathrm{K}$ & G & E & $\mathrm{S}$ & $\mathrm{T}$ & $\mathrm{T}$ & $\mathrm{D}$ & $\mathrm{D}$ & $\mathrm{S}$ \\
\hline Bristol 1993 & V & $\mathrm{S}$ & $\mathrm{H}$ & $\mathrm{D}$ & $\mathrm{T}$ & $\mathrm{N}$ & $\mathrm{L}$ & $\mathrm{K}$ & A & Q & $\mathrm{D}$ & - & $\mathrm{H}$ & $\mathrm{N}$ & $\mathrm{T}$ & $\mathrm{G}$ \\
\hline Camberwell 1994 & $\mathrm{~V}$ & $\mathrm{~S}$ & $\mathrm{H}$ & $\mathrm{D}$ & $\mathrm{T}$ & $\mathrm{N}$ & $\mathrm{L}$ & $\mathrm{K}$ & $\mathrm{A}$ & $\mathrm{Q}$ & $\mathrm{D}$ & - & $\mathrm{H}$ & $\mathrm{N}$ & $\mathrm{T}$ & $\mathrm{G}$ \\
\hline US95 96 & $\mathrm{~A}$ & $\mathrm{~S}$ & $\mathrm{H}$ & $\mathrm{D}$ & $\mathrm{T}$ & $\mathrm{N}$ & $\mathrm{M}$ & $\mathrm{K}$ & $\mathrm{E}$ & Q & $\mathrm{N}$ & - & $\mathrm{N}$ & $\mathrm{N}$ & $\mathrm{T}$ & $\mathrm{G}$ \\
\hline Farmington Hills 2002 & A & $\mathrm{T}$ & $\mathrm{H}$ & $\mathrm{N}$ & $\mathrm{N}$ & $\mathrm{N}$ & $\mathrm{M}$ & $\mathrm{K}$ & $\mathrm{G}$ & E & $\mathrm{N}$ & $\mathrm{G}$ & $\mathrm{T}$ & $\mathrm{S}$ & $\mathrm{T}$ & $\mathrm{G}$ \\
\hline Lanzhou 2002 & $\mathrm{~A}$ & $\mathrm{~T}$ & $\mathrm{H}$ & $\mathrm{D}$ & $\mathrm{T}$ & $\mathrm{N}$ & V & $\mathrm{K}$ & $\mathrm{G}$ & E & $\mathrm{N}$ & $\mathrm{S}$ & $\mathrm{T}$ & $\mathrm{N}$ & $\mathrm{T}$ & $\mathrm{G}$ \\
\hline Asia 2003 & $\mathrm{P}$ & $\mathrm{T}$ & $\mathrm{R}$ & $\mathrm{T}$ & $\mathrm{A}$ & $\mathrm{D}$ & $\mathrm{M}$ & $\mathrm{R}$ & G & $\mathrm{E}$ & $\mathrm{S}$ & $\mathrm{S}$ & $\mathrm{T}$ & $\mathrm{D}$ & $\mathrm{T}$ & $\mathrm{V}$ \\
\hline Kaiso 2003 & $\mathrm{~A}$ & $\mathrm{~S}$ & $\mathrm{R}$ & $\mathrm{N}$ & $\mathrm{S}$ & $\mathrm{D}$ & $\mathrm{L}$ & $\mathrm{K}$ & $\mathrm{A}$ & $\mathrm{Q}$ & $\mathrm{D}$ & - & $\mathrm{R}$ & $\mathrm{D}$ & $\mathrm{T}$ & G \\
\hline Hunter 2004 & A & $\mathrm{T}$ & $\mathrm{Q}$ & $\mathrm{N}$ & $\mathrm{S}$ & $\mathrm{S}$ & $\mathrm{V}$ & $\mathrm{R}$ & $\mathrm{R}$ & E & $\mathrm{S}$ & $\mathrm{T}$ & $\mathrm{T}$ & $\mathrm{D}$ & $\mathrm{D}$ & $\mathrm{S}$ \\
\hline Yerseke 2006a & $\mathrm{A}$ & $\mathrm{T}$ & $\mathrm{Q}$ & $E$ & $\mathrm{~S}$ & $\mathrm{~S}$ & $\mathrm{~V}$ & $\mathrm{R}$ & $\mathrm{R}$ & $\mathrm{E}$ & $\mathrm{S}$ & $\mathrm{T}$ & $\mathrm{T}$ & $\mathrm{N}$ & $\mathrm{D}$ & $\mathrm{S}$ \\
\hline Den Haag 2006b & $\mathrm{A}$ & $\mathrm{S}$ & $\mathrm{R}$ & $\mathrm{N}$ & $\mathrm{S}$ & $\mathrm{E}$ & $\mathrm{V}$ & $\mathrm{K}$ & $\mathrm{G}$ & $\mathrm{E}$ & $\mathrm{S}$ & $\mathrm{T}$ & $\mathrm{T}$ & $\mathrm{S}$ & $\mathrm{N}$ & $\mathrm{V}$ \\
\hline Apeldoorn 2007 & $\mathrm{~T}$ & $\mathrm{~S}$ & $\mathrm{R}$ & $\mathrm{N}$ & $\mathrm{A}$ & $\mathrm{D}$ & $\mathrm{V}$ & $\mathrm{K}$ & $\mathrm{A}$ & $\mathrm{D}$ & $\mathrm{D}$ & $\mathrm{T}$ & $\mathrm{A}$ & $\mathrm{S}$ & $\mathrm{N}$ & $\mathrm{S}$ \\
\hline Cairo 2007 & $\mathrm{~A}$ & $\mathrm{~S}$ & $\mathrm{R}$ & $\mathrm{N}$ & $\mathrm{A}$ & D & $\mathrm{M}$ & $\mathrm{K}$ & $\mathrm{G}$ & E & $\mathrm{N}$ & $\mathrm{T}$ & $\mathrm{T}$ & $\mathrm{G}$ & D & $\mathrm{G}$ \\
\hline Osaka 2007 & $\mathrm{~A}$ & $\mathrm{~S}$ & $\mathrm{R}$ & $\mathrm{N}$ & $\mathrm{A}$ & $\mathrm{D}$ & $\mathrm{M}$ & $\mathrm{K}$ & $\mathrm{S}$ & E & $\mathrm{S}$ & $\mathrm{T}$ & $\mathrm{T}$ & $\mathrm{N}$ & $\mathrm{T}$ & $\mathrm{G}$ \\
\hline New Orleans 2009 & $\mathrm{P}$ & $\mathrm{S}$ & $\mathrm{R}$ & $\mathrm{N}$ & $\mathrm{A}$ & D & $\mathrm{V}$ & $\mathrm{K}$ & $\mathrm{T}$ & E & $\mathrm{S}$ & $\mathrm{T}$ & $\mathrm{T}$ & $\mathrm{S}$ & $\mathrm{N}$ & I \\
\hline Sydney 2012 & $\mathrm{~T}$ & $\mathrm{~S}$ & $\mathrm{R}$ & $\mathrm{N}$ & $\mathrm{E}$ & D & V & $\mathrm{K}$ & $\mathrm{T}$ & E & $\mathrm{S}$ & $\mathrm{T}$ & $\mathrm{T}$ & $\mathrm{S}$ & $\mathrm{N}$ & $\mathrm{T}$ \\
\hline Hong Kong 2019 & A & $\mathrm{T}$ & $\mathrm{R}$ & $Q$ & $\mathrm{G}$ & $\mathrm{E}$ & $M$ & $\mathrm{~K}$ & G & Q & $\mathrm{E}$ & $\mathrm{N}$ & $\mathrm{P}$ & $\mathrm{S}$ & $\mathrm{T}$ & G \\
\hline
\end{tabular}

(b)
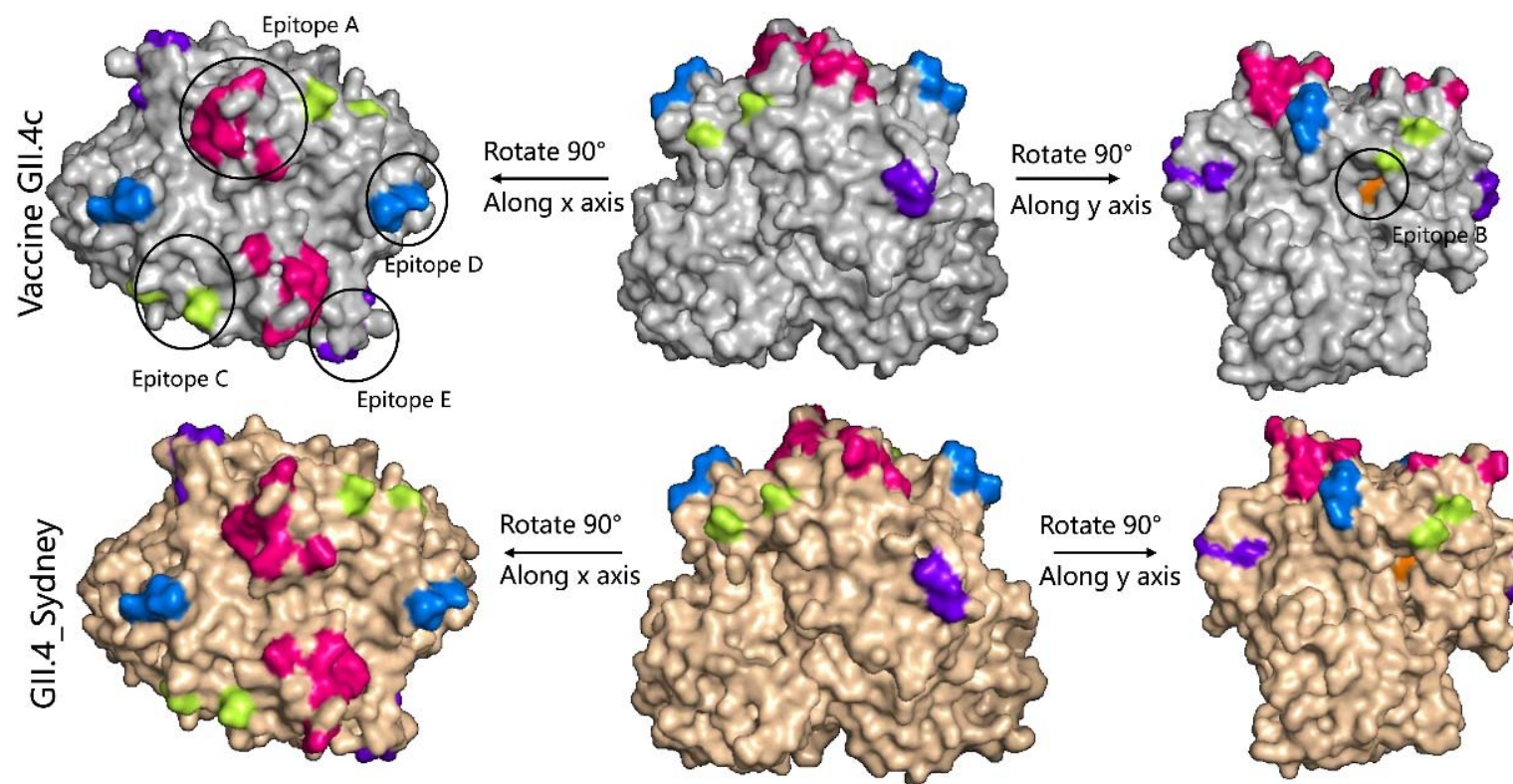

Top view

Front view

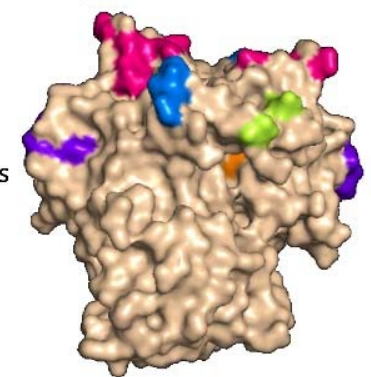

Side view

Figure 4. Cont. 
(c)
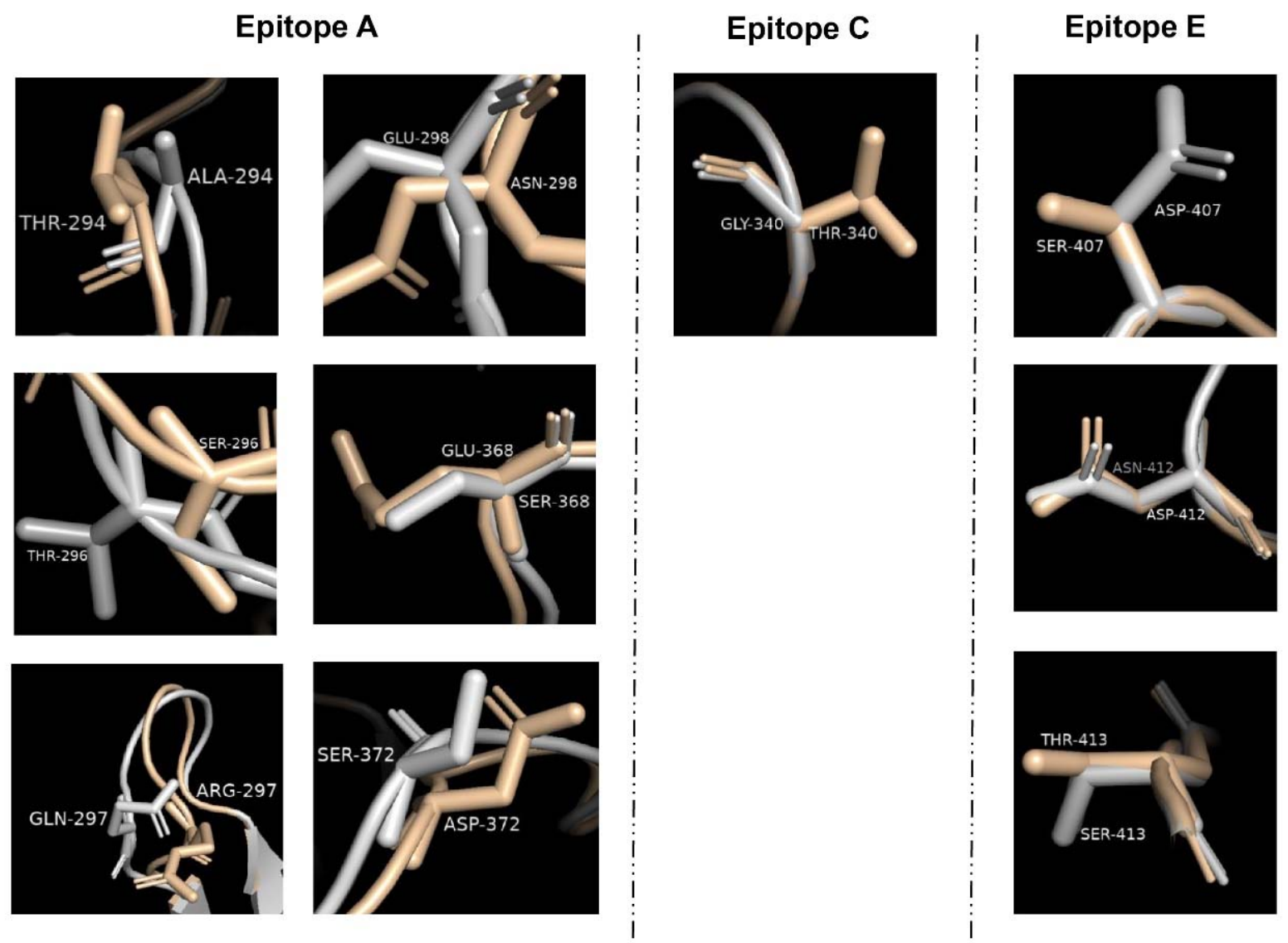

Figure 4. Predicted GII.4 norovirus evolving blockade epitopes. Bioinformatic approaches predicted five antibody epitopes on the surface of GII.4 noroviruses that appeared to be evolving over time and to correlate with the emergence of new GII.4 outbreak strains. (a) Amino acid variation of Epitopes A-E by GII.4 variant. (b) Surface representation of Sydney_2012 (brown) and GII.4c (grey). Epitope A (plum red), Epitope B (orange), Epitope C (lemon yellow), Epitope D (blue) and Epitope E (purple) are mapped onto P-dimer. (c) Cartoon representation of the subtle changes of blockade epitopes.

Another potential substantial change of the epitopes could be caused by the deletion at site 394 in the four early variants of Bristol_1993, Camberwell_1994, US95_96 and Kaiso_2003. Finally, the epitopes A and E of the currently predominant variant Sydney_2012 differed completely from those of the vaccine strain GII.4c, while one amino acid mutation was also found in epitope $C$ (Figure $4 b, c)$. These substantial differences could potentially result in antigenicity drifting events between the two GII.4 variants, raising concerns on the protective efficacy of the vaccine candidate against the currently predominant GII.4 variant Sydney_2012.

\section{Discussion}

In this study, we analyzed and demonstrated the molecular evolution patterns of the predominant NoV genotypes, including GII.4, GII.2, GII.3, GII.6 and GII.17 based on their complete sequences of capsid protein VP1-encoding genes collected from NoVs that circulated over the past 40-50 years. Due to the known epochal evolution [19], novel GII.4 variants that cause epidemics or pandemics have emerged every 2 to 3 years, replacing the previous variants, and spread rapidly in the human population. By contrast, the genotypes GII.2, GII.3 and GII.6 presented a relatively lower evolutionary rate with fewer variants that could persist and co-circulate over the past 40-50 years without frequent substitutions or turnovers of variants. These findings explain the epidemiological characteristics of 
various NoVs in human population, that is, GII.4 is the main epidemic genotype in adults, while GII.2, GII.3 and GII.6 NoVs circulate with GII.4 among children [20-22]. Owing to the long-term circulation of the same GII.2, GII.3 and GII.6 variants, the child would establish the effective immune barrier upon infection after birth; as a result, the GII.2, GII.3 and GII.6 genotypes are often seen among adults. In contrast, people are always susceptible to GII.4 NoVs due to frequent emergences of new variants [14]. Based on current understanding, the GII.4 persistence in human populations might be promoted by the antigenic drift, which is suggested by the variation in surface-exposed residues and in residues around the fucose ligand interaction domain [23]. Nevertheless, in the preliminary data from an ongoing birth cohort study conducted in infants, we did detect a few infants with longer asymptomatic shedding ( $>1$ month) after clinical recovery. Thus, we might speculate boldly that these excessively long shedding events serve as possible reservoirs for the high recombination rate in the population. Certainly, considering the widespread existence of norovirus in humans and animals, it might be another source that is responsible for the recombination. However, recent studies $[24,25]$ indicate that evidence for transmission of animal norovirus to humans is sparse; therefore, based on the current body of evidence, an association between animal norovirus and reservoir for humans could not be established at this moment.

Of note, the emergence of a novel GII.17 variant after long-term silence resulted in the short-term outbreaks in winter of 2014-2015. It was found that this new variant was more common in older children and adults. For instance, as described in a hospitalbased diarrhea surveillance in Shanghai, GII.17 (51.2\%, 22/43) was more detected in adults ( $>15$ years old), while no GII.17 $(0 \%, 0 / 35)$ was detected in children $(<15$ years old) [26]. In another study among the hospitalized cases of acute gastroenteritis in Hong Kong, the proportions of GII.17 infected individuals were $15.6 \%, 47.7 \%$ and $36.7 \%$ in the $<5$ years, 5-65 years and $>65$ years age groups, respectively [27]. A possible explanation for these observations was that there was greater competitive pressure on the new variant of GII.17 for young children due to the co-circulation of the GII.4, GII.2, GII.3 and GII.6 genotypes. However, the immune barrier had been established in older children and adults attributed to their childhood infection. Only the alternative GII.4 variant had a competitive relationship with new emerging GII.17 variant, which led to more chance of infection for GII.17.

At present, the cross-protection between genotypes/variants and whether a candidate vaccine will induce a broad spectrum of immunity remain unknown. The notion that epitopes A $(294,296-298,368,372)$ and E $(407,412-413)$ of the currently prevalent GII.4 variant Sydney_2012 are distinct from those of the vaccine strain GII.4c raises concerns about the potential lacking of cross-protection the candidate vaccine that is currently under phase IIb clinical trial [17]. Previous studies showed that epitope A likely formed a noncontiguous, conformational epitope that changed over time, suggesting its important role associated with immune escape [28]. On the other hand, epitope $E$ is found in surfaceexposed regions lateral to the histo-blood group antigens (HBGAs) binding pockets. The compositions of epitope $E$ varied with every major epidemic variant after 2002, indicating that it was a hot spot for the emergence of immunologically novel GII.4 variants [18]. In the phase I clinical trial, cross-reactive IgG to GII.2, GII.3 and GII.14 VLPs were observed after vaccination of bivalent GII.1/GII.4c VLPs vaccine [29]. Moreover, a recent study has demonstrated that the levels of HBGA-blocking antibodies and Pan-Ig induced by the GII.4c VLPs were increased in some placebo acute gastroenteritis (AGE) cases infected with GII.2. These findings suggested the vaccine strain GII.4c may possess a certain degree of cross-protection to other genotypes within the same genogroup [17].

According to the estimations by molecular clock model, the mean evolutionary rate of GII.4 was $4.95 \times 10^{-3}-5.91 \times 10^{-3}$ nucleotide substitutions/site/year, with emergences of 16 variants over the past several decades, which were consistent with those reported earlier studies (4.30 $\times 10^{-3}-7.68 \times 10^{-3}$ nucleotide substitutions/site/year) [30-33]. However, a lower rate $\left(1.55 \times 10^{-3}-2.97 \times 10^{-3}\right.$ nucleotide substitutions/site/year $)$ was observed in 
our NoV surveillance in Zhengding County. This finding suggested that evolution patterns may be conserved, overall, but they could also be different in a specific population in a specific area. It was noted that the new variant Hong_Kong_2019 that was first isolated from a female patient with AGEs in August 2019 shared 92.6\% amino acid sequence homology with capsid of the variant Osaka_2007 (GenBank: GQ845369) [34]. Considering that variant Sydney_2012 has been predominant since 2012, the emergence of variant Hong_Kong_2019 may indicate a new round of variant replacement.

GII.2 NoVs were rarely reported worldwide before 2016, with a few exception cases in Japan $[35,36]$. This study showed a mean evolutionary rate of $2.30 \times 10^{-3}-3.16 \times 10^{-3}$ nucleotide substitutions/site/year of GII.6 that was similar to that reported in previous studies $\left(2.99 \times 10^{-3}-3.24 \times 10^{-3}\right.$ nucleotide substitutions/site/year $)$ [14,37]. We noted that VP1 sequences of the currently prevalent GII.2 strain differed only slightly $(\sim 2.3 \%)$ compared with one circulated in the 1970s. Interestingly, the capsid sequence of the strain GII.P2/GII.2 that emerged in 2016 is highly similar to that of the strain GII.P16/GII.2 [38]. Because the GII.P16/GII.2 caused a sharp increase in AGE outbreaks in many countries in Asia and Europe in the winter of 2016-2017, the major factors leading to the re-emergence of GII.P16/GII.2 and the increase of AGE outbreaks must be in the genome regions other than the capsid protein-encoding genes [10]. For example, the GII.P16 polymerase may confer the new strain/variant a better adaptability compared with the GII.P2 polymerase. As CaliciNet reported during 2016-2018, 81.2\% of AGE outbreaks were caused by GII.P16/GII.2 in China [39].

Unlike GII.4 NoVs that caused AGE in people of all age groups, some previous reports have suggested that GII.3 is the predominant genotype in infants and children, implying a sustained, lifelong protection [40,41]. As found in our study, although the mean evolutionary rate of GII.3 $\left(3.40 \times 10^{-3}-3.59 \times 10^{-3}\right.$ nucleotide substitutions/site/year $)$ is comparable to other non-GII.4 genotypes, the amino acid variation of GII.3 VP1 was so little that no novel variant had emerged since 1970s. This may be the main reason for the low prevalence of GII.3 in recent years.

The first report of GII.6 NoVs was in 1971 in Henryton Hospital of Maryland, USA [42]. Our study identified three GII.6 variants (GII.6a, GII.6b and GII.6c) circulated since the 1970s, which is concordant with the results of earlier studies [43]. Although genotype GII.6 failed to present a linear relationship over time $\left(R^{2}=0.170\right)$, it showed a strong linear evolution trend $\left(R^{2}=0.88-0.98\right)$ when the three variants were analyzed separately, indicating a unique evolutionary mechanism [15]. So far, there have been only a few reports of AGE caused by GII.6 NoVs. For instance, GII.6 strains emerged as the second most prevailing strain after GII.4, causing AGE in children in Shizuoka, Japan, during 2008-2009 [44]. In addition, an AGE outbreak occurred in an elementary school in Shanghai in December of 2013 [45]. As reported in the United States from 2014 to 2015, 10.3\% (94/910) of the NoV outbreaks were attributed to GII.6 NoVs [46]. Moreover, according to NoroNet, the NoV surveillance network, GII.6 accounted for 2.0-10.3\% of NoV outbreaks and sporadic cases between 2005 and 2016 in Europe, Asia, Oceania and Africa [47]. Despite a lack of statistical significance in the year-to-year difference of GII.6-associated diseases, the large-scale epidemiological surveys and systematic reviews of NoV literatures showed that GII. 6 was the second common genotype after GII.4.

The earliest GII.17 sequence available in the National Center for Biotechnology Information (NCBI) database was from a stool sample collected back in 1978 [48]. Since then, there were only a few reports of sporadic cases caused by GII.17 around the world and occasional detection of this genotype in environmental samples [49]. During the winter of 2014-2015, the novel GII.17 variant (designated variant D in this study) emerged to cause AGE outbreaks in East Asia [6]. As shown in a phylogenetic tree, pre-epidemic variant $C$ and epidemic variant D of GII.17 shared a common ancestry and then diverged into two genetically distinct variants. Sang et al. [50] showed that their P2 subdomains are highly variable with $44 \%(56 / 128)$ amino acids variations, including two insertions at positions 295-296 and one deletion at position 385 (variants C and D) and one insertion at 
position 375 (variant D). These amino acid insertions and deletions may lead to the evasion of herd immunity and the change of population susceptibility, which may explain the high prevalence of GII.17 variant D.

There are several limitations in this study. Firstly, the virus RNA showed some degradation due to the long-term storage of stool specimens collected for NoV surveillance from Zhengding County, which made it difficult to detect NoVs. Secondly, most of the sequences were from GenBank database, which may not represent the actual status of NoV infections. However, we believed that the source of NoV sequences may not be as important as the molecular epidemiological trend and evolutionary patterns of NoV variants identified by our analysis. Furthermore, sequences from population-based surveillance in Zhengding County confirmed the reliability and consistency of results based on the sequences from GenBank database. Thirdly, due to the limitation of computer capabilities, only representative GII.4 sequences were selected for our analysis.

\section{Materials and Methods}

\subsection{Dataset from Population-Based Diarrhea Surveillance}

\subsubsection{Sample Collection}

The time serial stool samples were collected from five surveillance groups of children under five years old in Zhengding County, Hebei Province, China, which covers the epidemic seasons from 2001 to 2019. The samples were 313, 338, 1091, 295 and 5363 for 2001-2002, 2004-2005, 2011-2012, 2016-2017 and 2018-2019, respectively. All bulk stools were stored at $-80^{\circ} \mathrm{C}$ until batch testing at the Key Laboratory of Medical Molecular Virology, Fudan University at the end of surveillance period.

\subsubsection{Complete VP1 Sequencing}

Nucleic acid was extracted from stool supernatant by an automated bead-beating procedure using TianLong Stool DNA/RNA Extraction Kit (TianLong Science \& Technology, Xi'an, China). The capsid protein-encoding regions of NoV genomes were amplified by conventional reverse transcription polymerase chain reaction (RT-PCR) using primers G1SKF/G1SKR and COG2F/G2SKR, as described previously [51]. All NoV-positive samples were selected for further sequencing of the complete VP1-encoding genes. RT was performed using GoScript ${ }^{\mathrm{TM}}$ Reverse Transcription System (Promega, Madison, WI, USA) with primer TX30SXN according to the manufacturer's instructions. PCR to amplify a $\sim 2.5 \mathrm{~kb}$ cDNA fragment covering the complete VP1 and VP2-encoding genes of NoV genome were performed using PrimeSTAR ${ }^{\circledR}$ HS DNA Polymerase (TaKaRa, Kusatsu, Japan) using a semi-nested PCR GII-specific primer set (GoG2F/Tx30SXN in the first-round PCR and G2SKF/Tx30SXN for the second-round PCR) for GII genogroup [52] and a one-step PCR GI-specific primer set (G1SKF/TX30SXN) for GI genogroup [53]. The cycling conditions included a denaturation step at $98^{\circ} \mathrm{C}$ for $3 \mathrm{~min}$; followed by 40 cycles of $98{ }^{\circ} \mathrm{C}$ for $10 \mathrm{~s}$, $60{ }^{\circ} \mathrm{C}$ for $15 \mathrm{~s}$ and $72{ }^{\circ} \mathrm{C}$ for $3 \mathrm{~min}$; followed by a final extension step at $72{ }^{\circ} \mathrm{C}$ for $10 \mathrm{~min}$. All PCR products were purified and sequenced using Sanger dideoxy termination sequencing by the Biosune Co., Ltd. in Shanghai. After sequencing, the Basic Local Alignment Search Tool (BLAST) was applied to identify genotypes.

\subsection{Dataset from GenBank}

All available NoV sequences were retrieved by searching the corresponding taxonomy ID (142786) from human host in GenBank database (accessed on 1 January 2020). The sequences with sampling time and capsid protein genotyping information were screened and retained to analyze temporal distribution of NoV genotypes together with the sequences from our surveillance in Zhengding County.

\subsection{Multiple Alignments and Phylogenetic Analyses}

The complete VP1 sequences of representative genotypes (GII.2, GII.3, GII.4, GII.6 and GII.17) were extracted using ORFfinder [54] for phylogenetic analysis. Sequences of 
each genotype from population-based diarrhea surveillance and GenBank were separately aligned using tool MUSCLE [55] in the Molecular Evolutionary Genetics Analysis (MEGA) software (version 7) with default parameters [56]. A neighbor-joining (NJ) phylogenetic tree based on the nucleotide alignment of full-length ORF2 was reconstructed using a maximum composite likelihood model supported by bootstrap with 1000 replicates and visualized in MEGA v7. The divergence pattern and clock-likeness of the VP1-encoding nucleotide sequences were visualized by root-to-tip divergence plots constructed by TempEst v1.5.3 (formerly called Path-O-Gen) using phylogenetic tree and collection year of each strain [57]. The best-fitting root option was used to minimize the sum of the squared residuals to obtain the best correlation of the root-to-tip divergence. The nomenclature for the GII.4 variants was determined using an online NoV typing tool [58]. For non-GII.4 genotypes, variants were defined by a cutoff of $5 \%$ difference in amino acid sequences, combined with the phylogenetic tree [14].

\subsection{Evolutionary Dynamic Analyses}

In addition, the parameter values for the best-fit model of nucleotide substitution rates were determined to be GTR+G+I using the Akalike Information Criterion (AIC) as implemented in jModelTest v2.1.3 [59]. The Bayesian Markov Chain Monte Carlo (MCMC) approach as implemented in BEAST software v1.10.4 package [60] was used to jointly estimate the annual nucleotide replacement rate of each site (subs./site/year) and the time to the most recent common ancestor (TMRCA) of each genotype. Since no specified demographic model that showed the known cyclic annual/seasonal behavior of the organism was available, the Bayesian skyline model for population growth was selected as a flexible coalescent tree using a strict or relaxed molecular clock model in BEAST [61]. For all models, the MCMC was run until the convergence of all the parameters was confirmed by visual inspection and effective sample size ( $>200$ in all parameters) using Tracer v1.7.1. The first 10\% of logs from the MCMC were removed as a burn-in before the posterior values were summarized. Statistical uncertainty in the parameter estimates was given by the $95 \%$ highest probability density (HPD) intervals. Different clock models, a strict molecular clock, an uncorrelated log-normal model (UCLN), and an uncorrelated exponential derivation model (UCED) were compared in Tracer v.1.6 by calculating the Bayes factor (BF) with 1000 bootstraps under the posterior distribution. TreeAnnotator v1.8.4 and FigTree v1.4.3 were used to summarize the posterior tree distribution and to visualize the annotated maximum clade credibility tree, respectively.

The genetic distance between vaccine strain GII.4c and the current prevalent genotypes/variants was compared at an amino acid level using MEGA v7. The bivalent GI.1/GII.4c VLPs vaccine was developed by Takeda Pharmaceutical Company Limited. The vaccine strain GII.4c (GenBank accession: MK614455.1) [62], a consensus sequence deriving from GII.4 Houston_2002, Den_Haag_2006b and Yerseke_2006a strains was downloaded from GenBank.

\subsection{Homologous Modeling}

Three-dimensional structure of $\mathrm{P}$ domain was predicted by homology modeling using the Swiss Model server [63]. The model was built based on the published crystal structures of GII.4 NoV strain VA387 (PDB accession code: 2ORB) [64]. Residue changes in blocking epitopes between the vaccine strain GII.4c and the variant Sydney_2012 were mapped to the model by PyMol v1.3. Residue positions were numbered according to the reference strain (GenBank accession: JX459908).

\section{Conclusions}

A comprehensive understanding of the evolutionary patterns employed by different NoV genotypes is essential for vaccine design and development, including selection of suitable NoV strains as immunogen of vaccine candidates. In this study, Sydney_2012 variant of GII.4, variant A of GII.2, a strain of GII.3, variant B and C of GII.6 and variant D 
of GII.17 were preliminarily considered to be included in the immunogen of a candidate vaccine for broad efficacy. In addition, continual surveillance of future NoVs will be necessary to update the vaccine formula as needed.

Supplementary Materials: The following are available online at https: / www.mdpi.com/article / 10.3390/pathogens10081012/s1, Table S1: The sequences of NoV GII.4 selected for analyses in this study.

Author Contributions: Conceptualization, X.-Y.W.; Methodology, H.-L.Z. and T.-Y.Q.; Formal Analysis, H.-L.Z.; Investigation, H.-L.Z., L.-N.C., S.-M.W. and C.Q.; Data Curation, H.-L.Z.; WritingOriginal Draft Preparation, H.-L.Z.; Writing-Review and Editing, X.-Y.W., T.-Y.Q. and M.T.; Funding Acquisition, S.-M.W. All authors have read and agreed to the published version of the manuscript.

Funding: This work was supported by the National Science and Technology Major Projects for Significant New Drugs Development (2018ZX09739002-006).

Institutional Review Board Statement: Not applicable.

Informed Consent Statement: Not applicable.

Data Availability Statement: The data that support the findings of this study are available from the corresponding author upon reasonable request.

Acknowledgments: We would like to acknowledge Lei Liu's team for providing server for bioinformatics analysis.

Conflicts of Interest: The authors declare no conflict of interest.

\section{References}

1. Troeger, C.; Blacker, B.F.; Khalil, I.A.; Rao, P.C.; Cao, S.; Zimsen, S.R.M.; Albertson, S.B.; Stanaway, J.D.; Deshpande, A.; Abebe, Z.; et al. Estimates of the global, regional, and national morbidity, mortality, and aetiologies of diarrhoea in 195 countries: A systematic analysis for the Global Burden of Disease Study 2016. Lancet Infect. Dis. 2018, 18, 1211-1228. [CrossRef]

2. Robilotti, E.; Deresinski, S.; Pinsky, B.A. Norovirus. Clin. Microbiol. Rev. 2015, 28, 134-164. [CrossRef]

3. Prasad, B.V.; Hardy, M.E.; Dokland, T.; Bella, J.; Rossmann, M.G.; Estes, M.K. X-ray crystallographic structure of the Norwalk virus capsid. Science 1999, 286, 287-290. [CrossRef]

4. Vinje, J. Advances in laboratory methods for detection and typing of norovirus. J. Clin. Microbiol. 2015, 53, 373-381. [CrossRef]

5. De Graaf, M.; van Beek, J.; Koopmans, M.P. Human norovirus transmission and evolution in a changing world. Nat. Rev. Microbiol. 2016, 14, 421-433. [CrossRef]

6. De Graaf, M.; van Beek, J.; Vennema, H.; Podkolzin, A.T.; Hewitt, J.; Bucardo, F.; Templeton, K.; Mans, J.; Nordgren, J.; Reuter, G.; et al. Emergence of a novel GII.17 norovirus-End of the GII.4 era. Eurosurveillance 2015, 20, 21178. [CrossRef]

7. Supadej, K.; Khamrin, P.; Kumthip, K.; Malasao, R.; Chaimongkol, N.; Saito, M.; Oshitani, H.; Ushijima, H.; Maneekarn, N. Distribution of norovirus and sapovirus genotypes with emergence of NoV GII.P16/GII.2 recombinant strains in Chiang Mai, Thailand. J. Med. Virol. 2019, 91, 215-224. [CrossRef] [PubMed]

8. Nagasawa, K.; Matsushima, Y.; Motoya, T.; Mizukoshi, F.; Ueki, Y.; Sakon, N.; Murakami, K.; Shimizu, T.; Okabe, N.; Nagata, N.; et al. Phylogeny and Immunoreactivity of Norovirus GII.P16-GII.2, Japan, Winter 2016-17. Emerg. Infect. Dis. 2018, 24, 144-148. [CrossRef] [PubMed]

9. Niendorf, S.; Jacobsen, S.; Faber, M.; Eis-Hübinger, A.M.; Hofmann, J.; Zimmermann, O.; Höhne, M.; Bock, C.T. Steep rise in norovirus cases and emergence of a new recombinant strain GII.P16-GII.2, Germany, winter 2016. Eurosurveillance 2017, $22,30447$. [CrossRef] [PubMed]

10. Ao, Y.Y.; Cong, X.; Jin, M.; Sun, X.M.; Wei, X.M.; Wang, J.J.; Zhang, Q.; Song, J.; Yu, J.M.; Cui, J.; et al. Genetic Analysis of Reemerging GII.P16-GII.2 Noroviruses in 2016-2017 in China. J. Infect. Dis. 2018, 218, 133-143. [CrossRef] [PubMed]

11. Clinical Trial of Quadrivalent Recombinant Norovirus Vaccine. High Tech Ind. 2019, 71.

12. Esposito, S.; Principi, N. Norovirus Vaccine: Priorities for Future Research and Development. Front. Immunol. 2020, 11, 1383. [CrossRef] [PubMed]

13. Cortes-Penfield, N.W.; Ramani, S.; Estes, M.K.; Atmar, R.L. Prospects and Challenges in the Development of a Norovirus Vaccine. Clin. Ther. 2017, 39, 1537-1549. [CrossRef] [PubMed]

14. Parra, G.I.; Squires, R.B.; Karangwa, C.K.; Johnson, J.A.; Lepore, C.J.; Sosnovtsev, S.V.; Green, K.Y. Static and Evolving Norovirus Genotypes: Implications for Epidemiology and Immunity. PLoS Pathog. 2017, 13, e1006136. [CrossRef] [PubMed]

15. Tohma, K.; Lepore, C.J.; Ford-Siltz, L.A.; Parra, G.I. Evolutionary dynamics of non-GII genotype 4 (GII.4) noroviruses reveal limited and independent diversification of variants. J. Gen. Virol. 2018, 99, 1027-1035. [CrossRef] [PubMed] 
16. Siqueira, J.A.M.; Bandeira, R.D.S.; Oliveira, D.S.; Dos Santos, L.F.P.; Gabbay, Y.B. Genotype diversity and molecular evolution of noroviruses: A 30-year (1982-2011) comprehensive study with children from Northern Brazil. PLoS ONE 2017, 12, e0178909. [CrossRef]

17. Sherwood, J.; Mendelman, P.M.; Lloyd, E.; Liu, M.; Boslego, J.; Borkowski, A.; Jackson, A.; Faix, D. Efficacy of an intramuscular bivalent norovirus GI.1/GII.4 virus-like particle vaccine candidate in healthy US adults. Vaccine 2020, 38, 6442-6449. [CrossRef]

18. Lindesmith, L.C.; Beltramello, M.; Donaldson, E.F.; Corti, D.; Swanstrom, J.; Debbink, K.; Lanzavecchia, A.; Baric, R.S. Immunogenetic mechanisms driving norovirus GII.4 antigenic variation. PLoS Pathog. 2012, 8, e1002705. [CrossRef]

19. Ruis, C.; Lindesmith, L.C.; Mallory, M.L.; Brewer-Jensen, P.D.; Bryant, J.M.; Costantini, V.; Monit, C.; Vinje, J.; Baric, R.S.; Goldstein, R.A.; et al. Preadaptation of pandemic GII.4 noroviruses in unsampled virus reservoirs years before emergence. Virus Evol. 2020, 6, veaa067. [CrossRef]

20. Chan, M.C.; Leung, T.F.; Chung, T.W.; Kwok, A.K.; Nelson, E.A.; Lee, N.; Chan, P.K. Virus Genotype Distribution and Virus Burden in Children and Adults Hospitalized for Norovirus Gastroenteritis, 2012-2014, Hong Kong. Sci. Rep. 2015, 5, 11507. [CrossRef]

21. Wu, X.; Han, J.; Chen, L.; Xu, D.; Shen, Y.; Zha, Y.; Zhu, X.; Ji, L. Prevalence and genetic diversity of noroviruses in adults with acute gastroenteritis in Huzhou, China, 2013-2014. Arch. Virol. 2015, 160, 1705-1713. [CrossRef]

22. Zakikhany, K.; Allen, D.J.; Brown, D.; Iturriza-Gomara, M. Molecular evolution of GII-4 Norovirus strains. PLoS ONE 2012, 7, e41625. [CrossRef] [PubMed]

23. Debbink, K.; Lindesmith, L.C.; Donaldson, E.F.; Costantini, V.; Beltramello, M.; Corti, D.; Swanstrom, J.; Lanzavecchia, A.; Vinje, J.; Baric, R.S. Emergence of new pandemic GII.4 Sydney norovirus strain correlates with escape from herd immunity. J. Infect. Dis. 2013, 208, 1877-1887. [CrossRef] [PubMed]

24. Villabruna, N.; Koopmans, M.P.G.; de Graaf, M. Animals as Reservoir for Human Norovirus. Viruses 2019, 11, 478. [CrossRef] [PubMed]

25. Karst, S.M.; Baric, R.S. What is the reservoir of emergent human norovirus strains? J. Virol. 2015, 89, 5756-5759. [CrossRef]

26. Chen, H.; Qian, F.; Xu, J.; Chan, M.; Shen, Z.; Zai, S.; Shan, M.; Cai, J.; Zhang, W.; He, J.; et al. A novel norovirus GII.17 lineage contributed to adult gastroenteritis in Shanghai, China, during the winter of 2014-2015. Emerg. Microbes Infect. 2015,4 , e67. [CrossRef] [PubMed]

27. Chan, M.C.; Lee, N.; Hung, T.N.; Kwok, K.; Cheung, K.; Tin, E.K.; Lai, R.W.; Nelson, E.A.; Leung, T.F.; Chan, P.K. Rapid emergence and predominance of a broadly recognizing and fast-evolving norovirus GII.17 variant in late 2014. Nat. Commun. 2015, 6, 10061. [CrossRef] [PubMed]

28. Debbink, K.; Donaldson, E.F.; Lindesmith, L.C.; Baric, R.S. Genetic mapping of a highly variable norovirus GII.4 blockade epitope: Potential role in escape from human herd immunity. J. Virol. 2012, 86, 1214-1226. [CrossRef]

29. Lindesmith, L.C.; Ferris, M.T.; Mullan, C.W.; Ferreira, J.; Debbink, K.; Swanstrom, J.; Richardson, C.; Goodwin, R.R.; Baehner, F.; Mendelman, P.M.; et al. Broad blockade antibody responses in human volunteers after immunization with a multivalent norovirus VLP candidate vaccine: Immunological analyses from a phase I clinical trial. PLoS Med. 2015, 12, e1001807. [CrossRef] [PubMed]

30. Motoya, T.; Nagasawa, K.; Matsushima, Y.; Nagata, N.; Ryo, A.; Sekizuka, T.; Yamashita, A.; Kuroda, M.; Morita, Y.; Suzuki, Y.; et al. Molecular Evolution of the VP1 Gene in Human Norovirus GII.4 Variants in 1974-2015. Front. Microbiol. 2017, 8, 2399. [CrossRef] [PubMed]

31. Bok, K.; Abente, E.J.; Realpe-Quintero, M.; Mitra, T.; Sosnovtsev, S.V.; Kapikian, A.Z.; Green, K.Y. Evolutionary dynamics of GII.4 noroviruses over a 34-year period. J. Virol. 2009, 83, 11890-11901. [CrossRef] [PubMed]

32. Qiao, N.; Wang, X.Y.; Liu, L. Temporal Evolutionary Dynamics of Norovirus GII.4 Variants in China between 2004 and 2015. PLoS ONE 2016, 11, e0163166. [CrossRef]

33. Siebenga, J.J.; Lemey, P.; Kosakovsky Pond, S.L.; Rambaut, A.; Vennema, H.; Koopmans, M. Phylodynamic reconstruction reveals norovirus GII.4 epidemic expansions and their molecular determinants. PLoS Pathog. 2010, 6, e1000884. [CrossRef] [PubMed]

34. Tse, E.H.Y.; Zhang, L.-Y.; Lau, S.-L.; Chan, M.C.-W. Genome Sequence of a Human Norovirus GII.4 Hong Kong [P31] Variant in Hong Kong, China. Microbiol. Resour. Announc. 2020, 9, e01391-19. [CrossRef] [PubMed]

35. Iritani, N.; Kaida, A.; Abe, N.; Sekiguchi, J.; Kubo, H.; Takakura, K.; Goto, K.; Ogura, H.; Seto, Y. Increase of GII.2 norovirus infections during the 2009-2010 season in Osaka City, Japan. J. Med. Virol. 2012, 84, 517-525. [CrossRef]

36. Iritani, N.; Kaida, A.; Kubo, H.; Abe, N.; Murakami, T.; Vennema, H.; Koopmans, M.; Takeda, N.; Ogura, H.; Seto, Y. Epidemic of genotype GII.2 noroviruses during spring 2004 in Osaka City, Japan. J. Clin. Microbiol. 2008, 46, 2406-2409. [CrossRef]

37. Tohma, K.; Lepore, C.J.; Ford-Siltz, L.A.; Parra, G.I. Phylogenetic Analyses Suggest that Factors Other Than the Capsid Protein Play a Role in the Epidemic Potential of GII.2 Norovirus. mSphere 2017, 2, e00187-17. [CrossRef] [PubMed]

38. Ao, Y.; Xie, X.; Dong, X.; Jin, M.; Duan, Z. Genetic Analysis of an Emerging GII.P2-GII.2 Norovirus Associated with a 2016 Outbreak of Acute Gastroenteritis in China. Virol. Sin. 2019, 34, 111-114. [CrossRef]

39. Jin, M.; Wu, S.; Kong, X.; Xie, H.; Fu, J.; He, Y.; Feng, W.; Liu, N.; Li, J.; Rainey, J.; et al. Norovirus Outbreak Surveillance, China, 2016-2018. Emerg. Infect. Dis. J. 2020, 26, 437. [CrossRef] [PubMed]

40. Liu, J.; Li, S.; Wang, C.; Zheng, L.; Ma, J.; Li, C.; Huo, Y.; Wang, Y. Genomic characterization of GII.3 noroviruses isolated from children in Zhengzhou city, China, 2015/16. Arch. Virol. 2018, 163, 2737-2742. [CrossRef] 
41. Boonchan, M.; Guntapong, R.; Sripirom, N.; Ruchusatsawat, K.; Singchai, P.; Rungnobhakhun, P.; Tacharoenmuang, R.; Mizushima, H.; Tatsumi, M.; Takeda, N.; et al. The dynamics of norovirus genotypes and genetic analysis of a novel recombinant GII.P12-GII.3 among infants and children in Bangkok, Thailand between 2014 and 2016. Infect. Genet. Evol. J. Mol. Epidemiol. Evol. Genet. Infect. Dis. 2018, 60, 133-139. [CrossRef]

42. Karangwa, C.K.; Parra, G.I.; Bok, K.; Johnson, J.A.; Levenson, E.A.; Green, K.Y. Sequential Gastroenteritis Outbreaks in a Single Year Caused by Norovirus Genotypes GII.2 and GII.6 in an Institutional Setting. Open Forum Infect. Dis. 2017, 4, ofx236. [CrossRef]

43. Epifanova, N.V. Genetic variants of norovirus of GII.6 genotype. Mol. Genet. Microbiol. Virol. 2016, 30, 192-200. [CrossRef]

44. Chan-It, W.; Thongprachum, A.; Khamrin, P.; Kobayashi, M.; Okitsu, S.; Mizuguchi, M.; Ushijima, H. Emergence of a new norovirus GII.6 variant in Japan, 2008-2009. J. Med. Virol. 2012, 84, 1089-1096. [CrossRef] [PubMed]

45. Luo, L.F.; Qiao, K.; Wang, X.G.; Ding, K.Y.; Su, H.L.; Li, C.Z.; Yan, H.J. Acute gastroenteritis outbreak caused by a GII.6 norovirus. World J. Gastroenterol. 2015, 21, 5295-5302. [CrossRef]

46. Cannon, J.L.; Barclay, L.; Collins, N.R.; Wikswo, M.E.; Castro, C.J.; Magana, L.C.; Gregoricus, N.; Marine, R.L.; Chhabra, P.; Vinje, J. Genetic and Epidemiologic Trends of Norovirus Outbreaks in the United States from 2013 to 2016 Demonstrated Emergence of Novel GII.4 Recombinant Viruses. J. Clin. Microbiol. 2017, 55, 2208-2221. [CrossRef] [PubMed]

47. Van Beek, J.; de Graaf, M.; Al-Hello, H.; Allen, D.J.; Ambert-Balay, K.; Botteldoorn, N.; Brytting, M.; Buesa, J.; Cabrerizo, M.; Chan, M.; et al. Molecular surveillance of norovirus, 2005-2016: An epidemiological analysis of data collected from the NoroNet network. Lancet Infect. Dis. 2018, 18, 545-553. [CrossRef]

48. Rackoff, L.A.; Bok, K.; Green, K.Y.; Kapikian, A.Z. Epidemiology and evolution of rotaviruses and noroviruses from an archival WHO Global Study in Children (1976-1979) with implications for vaccine design. PLoS ONE 2013, 8, e59394. [CrossRef] [PubMed]

49. Zhang, H.F.; Jin, M.; Li, Y.N.; Kang, H.H.; Duan, Z.J. The research progress on epidemic and evolutionary characteristics of norovirus GII.17. Chin. J. Front. Health Quar. 2017, 40, 136-140.

50. Sang, S.; Yang, X. Evolutionary dynamics of GII.17 norovirus. PeerJ 2018, 6, e4333. [CrossRef] [PubMed]

51. Wang, J.X.; Zhou, H.L.; Mo, Z.J.; Wang, S.M.; Hao, Z.Y.; Li, Y.; Zhen, S.S.; Zhang, C.J.; Zhang, X.J.; Ma, J.C.; et al. Burden of viral gastroenteritis in children living in rural China: Population-based surveillance. Int. J. Infect. Dis. IJID Off. Publ. Int. Soc. Infect. Dis. 2019, 90, 151-160. [CrossRef]

52. Motomura, K.; Oka, T.; Yokoyama, M.; Nakamura, H.; Mori, H.; Ode, H.; Hansman, G.S.; Katayama, K.; Kanda, T.; Tanaka, T.; et al. Identification of monomorphic and divergent haplotypes in the 2006-2007 norovirus GII/4 epidemic population by genomewide tracing of evolutionary history. J. Virol. 2008, 82, 11247-11262. [CrossRef] [PubMed]

53. Hansman, G.S.; Natori, K.; Shirato-Horikoshi, H.; Ogawa, S.; Oka, T.; Katayama, K.; Tanaka, T.; Miyoshi, T.; Sakae, K.; Kobayashi, S.; et al. Genetic and antigenic diversity among noroviruses. J. Gen. Virol. 2006, 87, 909-919. [CrossRef]

54. NCBI. Open Reading Frame Finder. Available online: https://www.ncbi.nlm.nih.gov/orffinder/ (accessed on 31 January 2020).

55. Edgar, R.C. MUSCLE: Multiple sequence alignment with high accuracy and high throughput. Nucleic Acids Res. 2004, 32, 1792-1797. [CrossRef] [PubMed]

56. Kumar, S.; Stecher, G.; Tamura, K. MEGA7: Molecular Evolutionary Genetics Analysis Version 7.0 for Bigger Datasets. Mol. Biol. Evol. 2016, 33, 1870-1874. [CrossRef] [PubMed]

57. Rambaut, A.; Lam, T.T.; Max Carvalho, L.; Pybus, O.G. Exploring the temporal structure of heterochronous sequences using TempEst (formerly Path-O-Gen). Virus Evol. 2016, 2, vew007. [CrossRef]

58. Kroneman, A.; Vennema, H.; Deforche, K.; Avoort, H.V.D.; Penaranda, S.; Oberste, M.S.; Vinje, J.; Koopmans, M. An automated genotyping tool for enteroviruses and noroviruses. J. Clin. Virol. Off. Publ. Pan Am. Soc. Clin. Virol. 2011, 51, 121-125. [CrossRef]

59. Darriba, D.; Taboada, G.L.; Doallo, R.; Posada, D. jModelTest 2: More models, new heuristics and parallel computing. Nat. Methods 2012, 9, 772. [CrossRef]

60. Drummond, A.J.; Suchard, M.A.; Xie, D.; Rambaut, A. Bayesian phylogenetics with BEAUti and the BEAST 1.7. Mol. Biol. Evol. 2012, 29, 1969-1973. [CrossRef]

61. Ho, S.Y.; Shapiro, B. Skyline-plot methods for estimating demographic history from nucleotide sequences. Mol. Ecol. Resour. 2011, 11, 423-434. [CrossRef]

62. Lindesmith, L.C.; McDaniel, J.R.; Changela, A.; Verardi, R.; Kerr, S.A.; Costantini, V.; Brewer-Jensen, P.D.; Mallory, M.L.; Voss, W.N.; Boutz, D.R.; et al. Sera Antibody Repertoire Analyses Reveal Mechanisms of Broad and Pandemic Strain Neutralizing Responses after Human Norovirus Vaccination. Immunity 2019, 50, 1530-1541.e8. [CrossRef] [PubMed]

63. Waterhouse, A.; Bertoni, M.; Bienert, S.; Studer, G.; Tauriello, G.; Gumienny, R.; Heer, F.T.; de Beer, T.A.P.; Rempfer, C.; Bordoli, L.; et al. SWISS-MODEL: Homology modelling of protein structures and complexes. Nucleic Acids Res. 2018, 46, W296-W303. [CrossRef] [PubMed]

64. Cao, S.; Lou, Z.; Tan, M.; Chen, Y.; Liu, Y.; Zhang, Z.; Zhang, X.C.; Jiang, X.; Li, X.; Rao, Z. Structural basis for the recognition of blood group trisaccharides by norovirus. J. Virol. 2007, 81, 5949-5957. [CrossRef] [PubMed] 